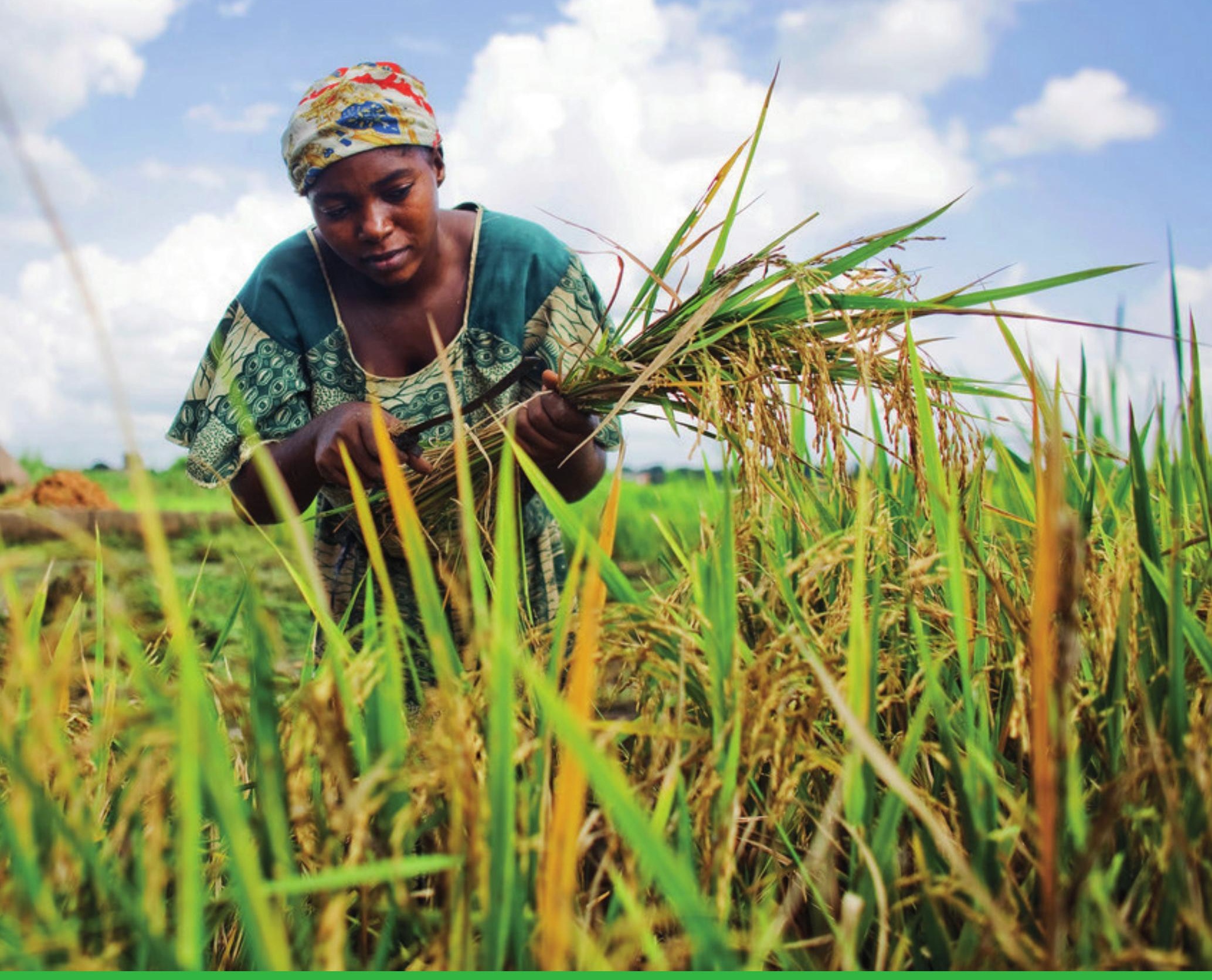

Food loss from harvest to farm gate in nine major cash crops - a review

R.B. Castelein MA MSc, dr.ir. J.M. Soethoudt, dr.ir. J. Broeze, H.B. Axmann MSc

WAGENINGEN

UNIVERSITY \& RESEARCH 



\section{Food loss from harvest to farm gate in nine major cash crops - a review}

Authors: Dr. R.B. (Bob) Castelein, dr.ir. J.M. (Han) Soethoudt, dr.ir. J. (Jan) Broeze, H.B. (Heike) Axmann MSc

Institute: Wageningen Food \& Biobased Research

This study was carried out by Wageningen Food \& Biobased Research and subsidised, funded and commissioned by Olam International. 
WFBR Project number: 6239202300

Version: Final

Reviewer: dr. X. (Xuezhen) Guo

Approved by: dr.ir. H. (Henk) Wensink

Subsidized by: Olam International

Sponsor: Olam International with co-support of the rice literature study by the CGIAR Research

Program on Climate Change, Agriculture and Food Security (CCAFS), which is carried out with support from the CGIAR Trust Fund and through bilateral funding agreements.

Confidentiality of the report: Public

The research that is documented in this report was conducted in an objective way by researchers who act impartial with respect to the client(s) and sponsor(s). This report can be downloaded for free at https://doi.org/10.18174/535690/ or at www.wur.eu/wfbr (under publications).

(C) 2021 Wageningen Food \& Biobased Research, institute within the legal entity Stichting Wageningen Research.

The client is entitled to disclose this report in full and make it available to third parties for review. Without prior written consent from Wageningen Food \& Biobased Research, it is not permitted to:

a. use this report for the purposes of making claims, conducting legal procedures, for (negative) publicity, and for recruitment in a more general sense;

b. use the name of Wageningen Food \& Biobased Research in a different sense than as the author of this report.

PO box 17, 6700 AA Wageningen, The Netherlands, T + 31 (0)317 4800 84, E info.wfbr@wur.nl, www.wur.eu/wfbr.

All rights reserved. No part of this publication may be reproduced, stored in a retrieval system of any nature, or transmitted, in any form or by any means, electronic, mechanical, photocopying, recording or otherwise, without the prior permission of the publisher. The publisher does not accept any liability for inaccuracies in this report. 


\section{Contents}

$\begin{array}{ll}\text { Summary } & 4\end{array}$

1 Introduction $\quad 5$

$\begin{array}{lll}2 & \text { Research approach } & 7\end{array}$

$\begin{array}{llr}3 & \text { Findings } & 8\end{array}$

3.1 Rice $\quad 8$

3.2 Sesame 11

3.3 Quinoa $r$

$\begin{array}{lll}3.4 & \text { Coffee } & 15\end{array}$

$\begin{array}{lll}3.5 & \text { Chillies and peppers } & 17\end{array}$

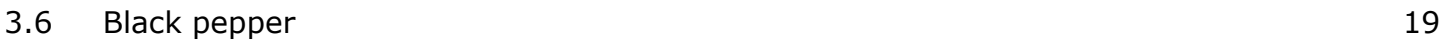

$\begin{array}{lll}3.7 & \text { Cashew } & 21\end{array}$

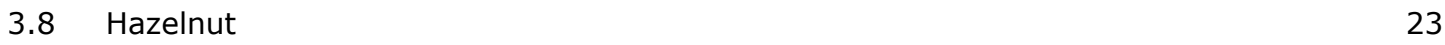

$\begin{array}{llr}3.9 \text { Cocoa } & 25\end{array}$

$4 \quad$ Discussion and conclusions $\quad 27$

$5 \quad$ Recommendations $\quad 30$

$\begin{array}{ll}\text { References } & 32\end{array}$ 


\section{Summary}

This study reports the findings of a literature review on food loss measurements in on-farm activities in the supply chains of nine major cash crops (rice, sesame, quinoa, coffee, chillies, black pepper, cashew, hazelnut and cocoa). Food loss assessments are essential to identify food loss hotspots and implement appropriate interventions to reduce loss. A literature review was conducted of studies focusing on these nine crops that report loss figures for specific activities. These figures were combined to compile comprehensive loss profiles for each crop and identify loss hotspots. For most crops, however, this has not been possible due to limited information availability. For those crops for which a more or less complete loss profile could be compiled, loss figures reported by the different studies diverged considerably, leading to wide ranges of possible total losses and no clear identification of loss hotspots. Moreover, discussion of the studies' used definitions, methodology, and research context show that overall reliability and comparability are limited. At present, the available primary data on specific product supply chains are too scattered to warrant actionable recommendations for improvements. The conclusions should serve as an impetus to address this data deficit, and solidify the evidence base to inform investment in interventions to reduce food loss in postharvest chains, specifically from harvest to farmgate. This not only pertains to the quality of data itself, but also entails harmonization of definitions and methodologies. Also for external funders, it is important to know where interventions can have the most impact, and for that purpose, the magnitude and hotspots of on-farm losses should be brought into focus more precisely and coherently, for a wide range of crops. For research in this domain, this requires alignment on definitions, methodologies, and reporting, as well as broad sharing of findings. 


\section{Introduction}

Approximately one-third of all food produced for consumption worldwide is lost or wasted before being consumed (FAO, 2011). Food loss and waste (FLW) is a threat to nutrition security, and food loss and waste-related greenhouse gas emissions are important drivers of climate change (Guo et al., 2020). This is equivalent to as much as about $8 \%$ of the total anthropogenic greenhouse gas (GHG) emissions. Globally, governments and private sector organizations have committed themselves to address these issues, as formulated in the sustainable development goals (SDGs - most relevant here being SDG 2 (Zero hunger), SDG 12 (Responsible production and consumption), SDG 13 (Take actions against climate change)) and shown in related initiatives such as Champions 12.3. Increasing understanding (on volumes and impacts) is essential to sustaining supply, improving the position of farmers and defining priorities for measures. Moreover, quantitative understanding will be essential when customers want to be informed about sustainability impacts of their products.

In the context of these efforts, Wageningen University and Research has been requested by Olam - a member of Champions 12.3 - to conduct an investigation of existing research on postharvest food losses from harvest to farmgate. This report contains the findings of this investigation, conducted independently and according to academic standards.

Despite growing awareness, governments and major food companies still have a limited insight into the extent and causes of food loss occurring on and close to farms, especially in small holderdominated supply chains. Global statistics on food loss may not reflect variations in production models and do not generally provide the practical insights that farmers and supply-chain managers need to address causality. Many types of food loss and waste data are available from all over the world. Thousands of articles and reports are written on this topic that has received increasing attention over the last ten years. For two years now, The Food Waste Atlas (2020) has aggregated the available information and enables users to search for FLW data based on criteria such as country, product (group), and part of the supply chain. This is for approximately $95 \%$ based on FAO food balance sheet calculations, and hence imputed figures rather than 'real' observed losses. This data is relevant for high-level analysis which can, for example, give direction to policymakers, but is limited in the extent to which it can support informed decisions about interventions in specific chains. Moreover, for specific chains, there are considerable data gaps, and several methodological options to fill these gaps. In specifying a data collection approach that is appropriate for the user, a number of factors should be weighed (Caldeira et al., 2017; Commission for Environmental Cooperation, 2019; Corrado et al., 2019; Fabi, 2019; Xue et al., 2017):

- Purpose (preliminary estimates or high-level national figures appropriate for policy measures)

- $\quad$ Resources (money, people)

- Time available

- Reliability

- Objectivity

- Accuracy

- Investigating causes

Depending on the needs and resources of the relevant stakeholder, a methodology can be chosen that strikes the correct balance between these criteria. For example, there is often a trade-off between resources and time available and the accuracy of the data, as detailed measurements tend to be costly and time-consuming. Methodologies can be categorized in direct and indirect measurements, yielding primary and secondary data respectively: 


\section{Table 1 Methodologies for FLW data collection.}

\begin{tabular}{ll} 
Primary data & Secondary data \\
Direct measurement (e.g. weighing) & Modelling \\
\hline Experiments (controlled) & Extrapolation from food balance sheets \\
Surveys & Use of proxy data \\
\hline Diaries & Secondary data from the literature \\
\hline Interviews & \\
\hline Focus groups & \\
Records & \\
\hline Observations &
\end{tabular}

Xue et al. (2020) evaluate these methods based on the factors discussed above, highlighting the relevant trade-offs between them. In general, FLW data for policymakers needs to be high-level with trends and estimates that are sufficient to give guidance to more general, mid- or long-term interventions. Many companies also pay attention to sustainability issues, including FLW reduction, and want to address this in a cost- and time-efficient way. However, these companies also deal with the particular conditions and span of control in their supply chains and hence require specific, accurate, and reliable data. High-level data will not provide insight into the feasibility of specific interventions in their part of the supply chain. The same applies to farmers that need guidance on which improvements are most appropriate for them.

In developed countries, most food is wasted ${ }^{1}$ on the retail- and household-level. In developing countries food loss early on in the chain is more prevalent, specifically high at the farms of smallholder farmers with limited resources and knowledge of causality of problems and potential solutions. For these smallholder farmers quantitative and qualitative food losses also entail economic losses that affect their livelihoods. The research that has been conducted so far in this domain based on the collection of primary data has been overall limited, and where available has focused predominantly on perishable crops and staple foods (Hodges, 2013; Stathers et al., 2020), and to a lesser extent on cash crops and globally traded dry commodities; nevertheless, huge on-farm postharvest losses are known to occur in some such crops (e.g. 35\% losses in Nigerian smallholder rice), with major impacts on the environmental footprint of the affected supply chains and the livelihood of the farmers involved. Such losses may be far larger than the farmer's own perceptions of loss, which are notoriously inaccurate (Kok \& Snel, 2019).

To take stock of the existing knowledge on a selection of these crops (including sesame, quinoa, coffee, chillies, black pepper, cashew, hazelnut, and cocoa - as well as rice as a more-researched crop), this report addresses the question: From literature research of previous investigations, what can we conclude about postharvest losses from harvest to farmgate of (a selection of) cash crops?

The scope of this study is limited to the supply chains of above-mentioned crops from harvest to farmgate, specifically what existing research has concluded about food losses in this part of the chain. Where the research has emphasized other notable sources of loss (either pre-harvest loss or selected logistics and processing losses) we highlight these but do not include them in the quantitative analysis. For each crop, the existing relevant literature is reviewed, and an attempt is made to compile a complete picture of food losses in postharvest activities and in total, in order to gauge the magnitude of losses and identify loss hotspots.

\footnotetext{
${ }^{1}$ Food loss being defined as a "decrease in quantity or quality of food for human consumption throughout the different segments of the food supply chains," and food waste being defined as the "discarding or alternative (non-food) use of food that is safe and nutritious for human consumption" (definitions from Kok \& Snel (2019), quoting Save Food Initiative (2015) and FAO (2014)).
} 


\section{Research approach}

We conducted a literature search focusing on these nine crops: rice, sesame, quinoa, coffee, chillies, black pepper, cashews, hazelnut, and cocoa, and searched for publications that report food loss and waste from harvest to farmgate. The investigation was conducted using CAB Abstracts, covering publications in international peer-reviewed journals, institutional reports, and university repositories. The search terms used included the crop names and common spelling variations and synonyms, in combination with the terms "loss OR losses OR waste OR wastes", occurring both in titles and abstracts. The search was limited to English-language publications from 2000 or more recently. In addition to this literature search, experts from Wageningen Food and Biobased research were asked to identify relevant research on the crops under consideration, after which duplicates were removed. Titles and abstracts were screened to filter out studies not covering food losses of the selected crops from harvest to farmgate. This approach should ensure that all (potentially) relevant studies are included, but 'unknown unknowns' can never be completely ruled out. Moreover, this approach yields relevant information insofar as it is publicly available - private, confidential, or otherwise not publicly available research is not included in this review.

From the remaining studies, the following information was collected:

- Country or region in which the study was conducted

- $\quad \operatorname{Crop}(\mathrm{s})$ discussed

- Postharvest activities reported on

- $\quad$ Method of data collection (see methodologies listed in table 1)

- $\quad$ Food losses reported per activity, and (if available) total on-farm losses

- Relevant information on contextual factors that could affect losses (e.g. farming practices)

- Specifically for rice, from a very large body of research, a selection was made of higherquality, more comprehensive, and comparable studies to review.

From this information, we proceed to compile - per crop - an overall impression of postharvest losses and evaluate the extent to which the available information allows us to do so. Qualitatively this includes a discussion of the information content and quality of the studies, including scope, definitions, methodology, comparability, and generalizability. The regional focus of the studies is compared to the most recent global production data from FAOstat (FAO, 2020).

From the available information per crop, crop-specific loss profiles are compiled with a range of loss values per activity, and the range of cumulative (total) on-farm losses. The lower and upper bounds of this cumulative range should constitute the best- and worst-case scenarios of food loss and a reasonable range within which actual losses are likely to be - depending on the overall availability and quality of information for a specific crop. The information from literature used as input for this research is taken at face value, in that one reported number is considered as one loss estimate without weighing the relative importance or reliability of the number in any way. 


\section{$3 \quad$ Findings}

This section outlines the findings regarding product losses in the postharvest chains from harvest to farmgate of 9 selected products: rice, sesame, quinoa, coffee, chillies, black pepper, cashew, hazelnut, and cocoa. For every commodity, we provide an overview of findings from previous studies, as obtained through the literature search process outlined above. This includes the regional focus of studies (related to global production), their scope, definitions and methodology used, and generalizability and comparability of the results. Each sub-section concludes with a systematic assessment of loss quantifications from previous studies - by supply chain activity and total on-farm losses - and a discussion of the conclusions that can be drawn from this.

\subsection{Rice}

Compared to other crops, food losses in the rice chain are relatively well-researched. This is probably related to the fact that rice is one of the major staple crops produced in quantities much larger than any of the other crops included in this study, and research specifically on rice is promoted through the International Rice Research Institute. Worldwide, 996.078.941 tonnes of rice are produced (2018), $21.5 \%$ of which is produced in China, $17.3 \%$ in India, $8.3 \%$ in Indonesia, and $5.7 \%$ in Bangladesh. Of the 11 studies reporting baseline loss figures for default production and processing methods, 4 were conducted in Bangladesh, 1 each in Nigeria, Ghana, India, Myanmar, and Iran, and 2 studies reported regional figures for South Asia and West Africa.

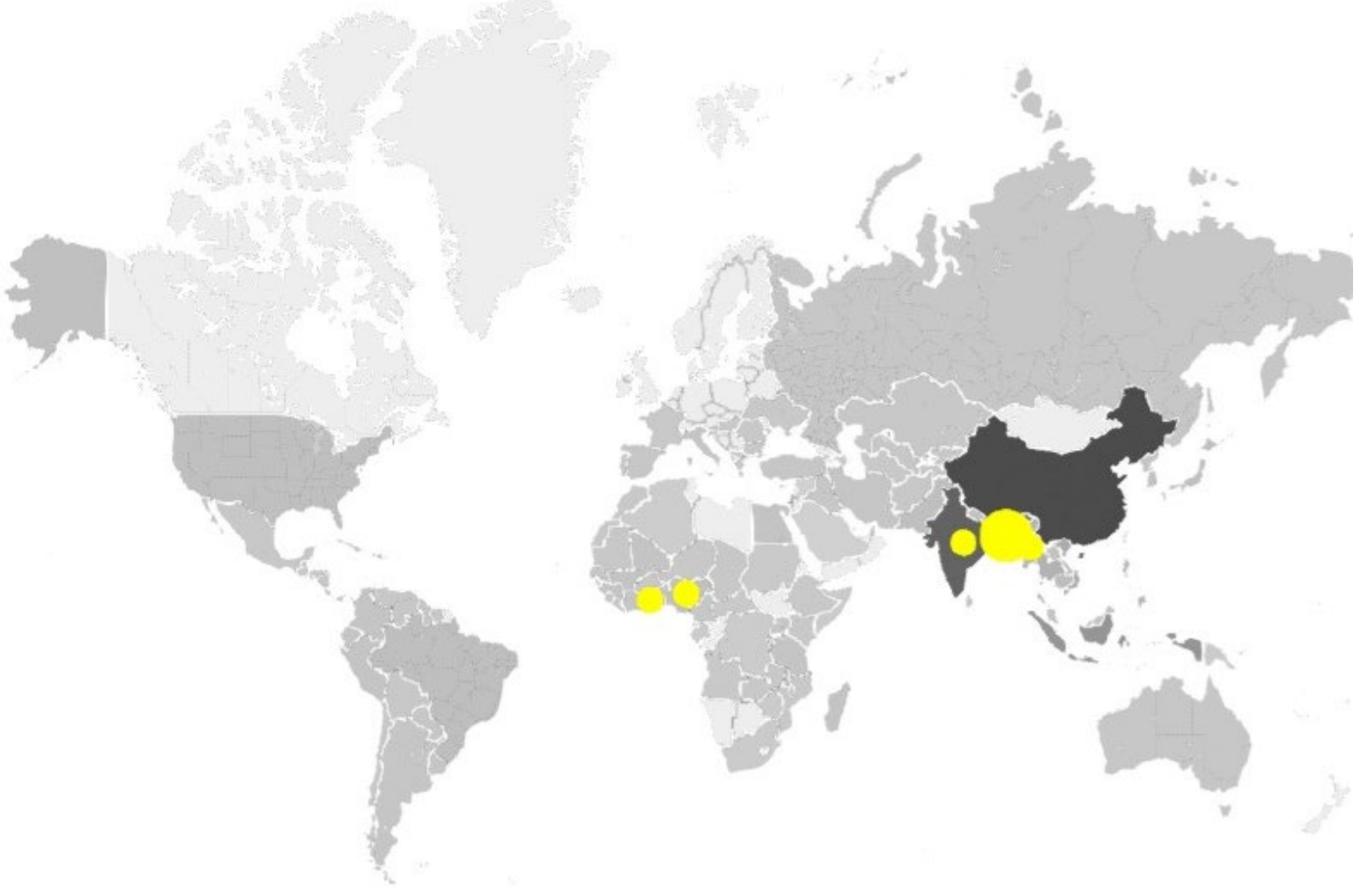

Figure 1 Countries' production of rice (rice, paddy) (tonnes, grayscale shading) and country focus of studies reviewed (yellow). Source: FAO (2020).

Out of the body of research on rice, 11 studies were selected that provide a fairly comprehensive overview of losses per activity in the rice chain. All these studies report losses for default (traditional) methods of rice production on smallholder farms, allowing us to establish a baseline loss profile with estimated lower and upper bound of losses with (relatively) similar production practices. Moreover, most studies also report the effect of one or more interventions. 
Definitions and measurements are relatively well-specified across these studies. Most importantly, activity definitions differ somewhat between studies - for example, some studies include on-farm transportation, others don't. The methodology used in studies differs considerably. The figure below shows the methods used in the studies reviewed focusing on rice.

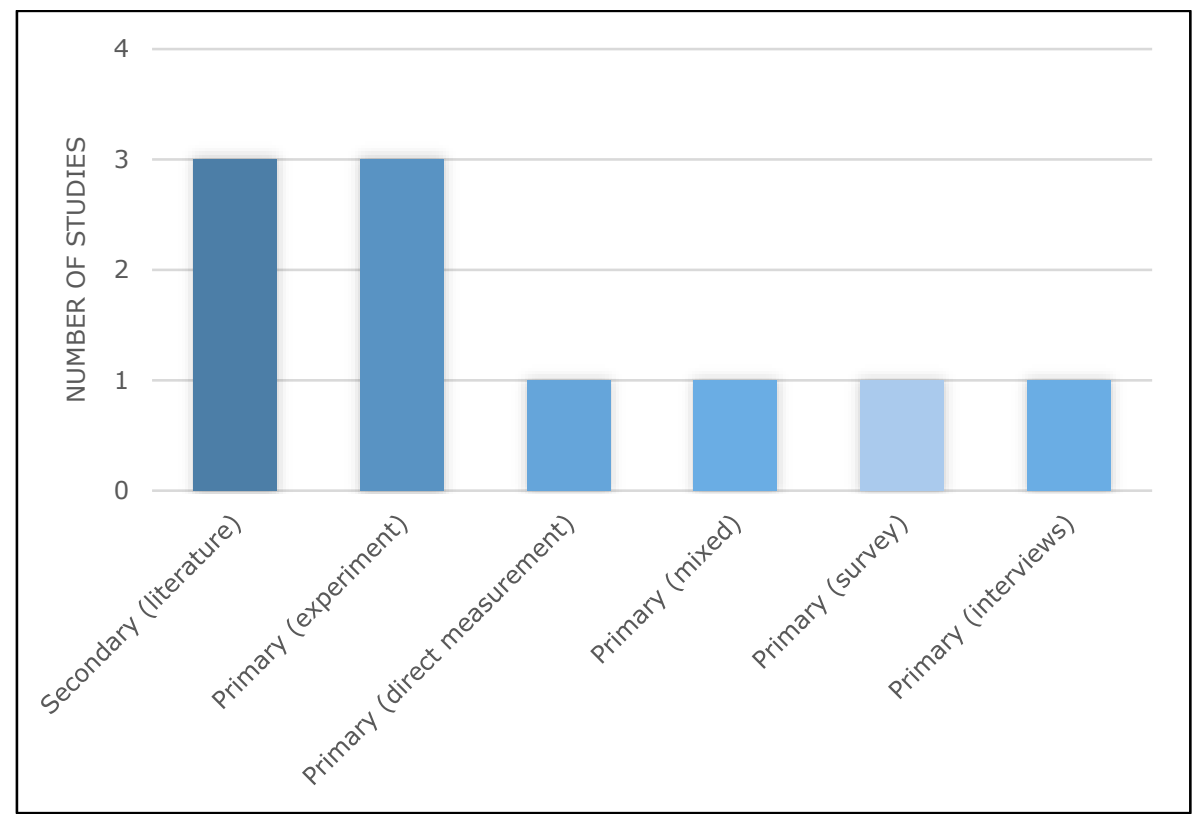

Figure 2 Approaches used in studies reviewed - Rice.

Most rely on some form of primary measurements, such as direct measurements on farms (Kok \& Snel, 2019) or a specific experimental setup in one setting (Alizadeh \& Allameh, 2013a; Jang \& Montanaro, 2014; Yusuf \& He, 2011). A smaller part of the research uses some form of self-reporting (e.g. surveys, interviews) (e.g. Bala et al., 2010). Others use a combination of both (Appiah et al., 2011), allowing to compare and contrast loss estimates from both - generally self-reporting measures tend to underestimate losses, compared to measurements (Kok \& Snel, 2019). Aside from these studies with primary data, a substantial subset of research relies purely on secondary data (Gummert, 2012; Kumar \& Kalita, 2017; Selvi et al., 2002).

This set of studies is probably more comparable than the research reviewed for other commodities because postharvest practices are kept (relatively) constant. The figure below shows the loss profile for rice based on these studies (note that not all studies report on all activities): 


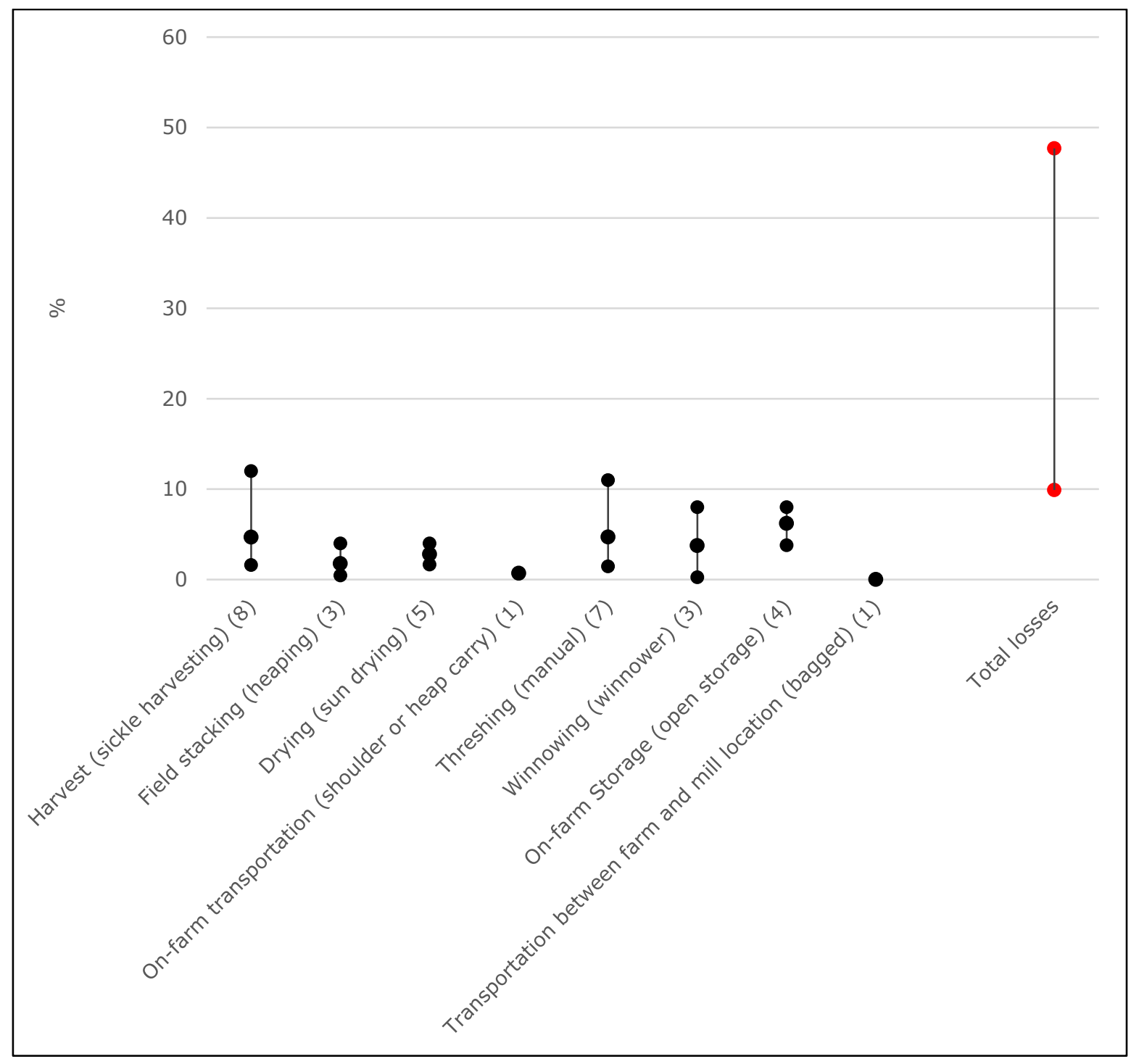

Figure 3 Rice - Averages and range of product losses at chain activities, upper and lower bound of total post-harvest losses. The number of loss estimates per activity indicated in parentheses. All for rice production with default methods.

Particularly in harvesting, threshing, and winnowing, there is a wide range of loss estimates. Judging by the average loss estimate per activity, on-farm storage seems to be a hotspot of food loss in the rice chain. Other hotspots could be harvesting, threshing, and winnowing, but the range of loss estimates for these activities indicates that an understanding of local practices is important. The drying stage deserves some discussion as well, as mass loss during drying can include water loss (the purpose of the drying process) or actual food or nutrition loss (e.g. due to rodents). From the studies surveyed, it is often not sure whether the figures include total losses or moisture adjusted losses or whether they account for this in a similar way. Still, the estimated range of losses in drying is quite narrow. Cumulatively, the possible range of postharvest losses is large, with a lower bound of $9.9 \%$ lost (assuming the lowest loss estimate per activity is true) and an upper bound of $47.69 \%$ (assuming the highest possible estimate per activity is true) - even when using data from studies that consider rice production with similar practices and techniques. One of the more comprehensive studies (Kok \& Snel, 2019) report an overall average loss of $35 \%$ in rice production on smallholder farms (towards the higher end of the total loss estimated from the compiled loss profile above), and mention that differences between farms were considerable, ranging from $8 \%$ to $55 \%$, which corresponds quite well with the worst and best-case scenarios from the loss profile above. Not included in this figure - due to the vastly different order of magnitude of losses - is the milling itself. Appiah et al. (2011) report milling yield (white rice weight as \% of paddy weight) of $47.3 \%$ for a local mill with $52.7 \%$ of grains being broken, and a yield of $67.3 \%$ with only $32.7 \%$ of broken grains for a more sophisticated milling machine (SB30). 
Most of the studies reviewed also evaluate the effect of one or more interventions in the rice chain, reducing losses in one specific activity compared to the baseline figures for losses using traditional practices shown above. Table 1 below shows per activity what interventions have been researched and what losses in that activity were reported after the introduction of the intervention.

Table 2 Rice-Reported post-harvest interventions and associated product loss.

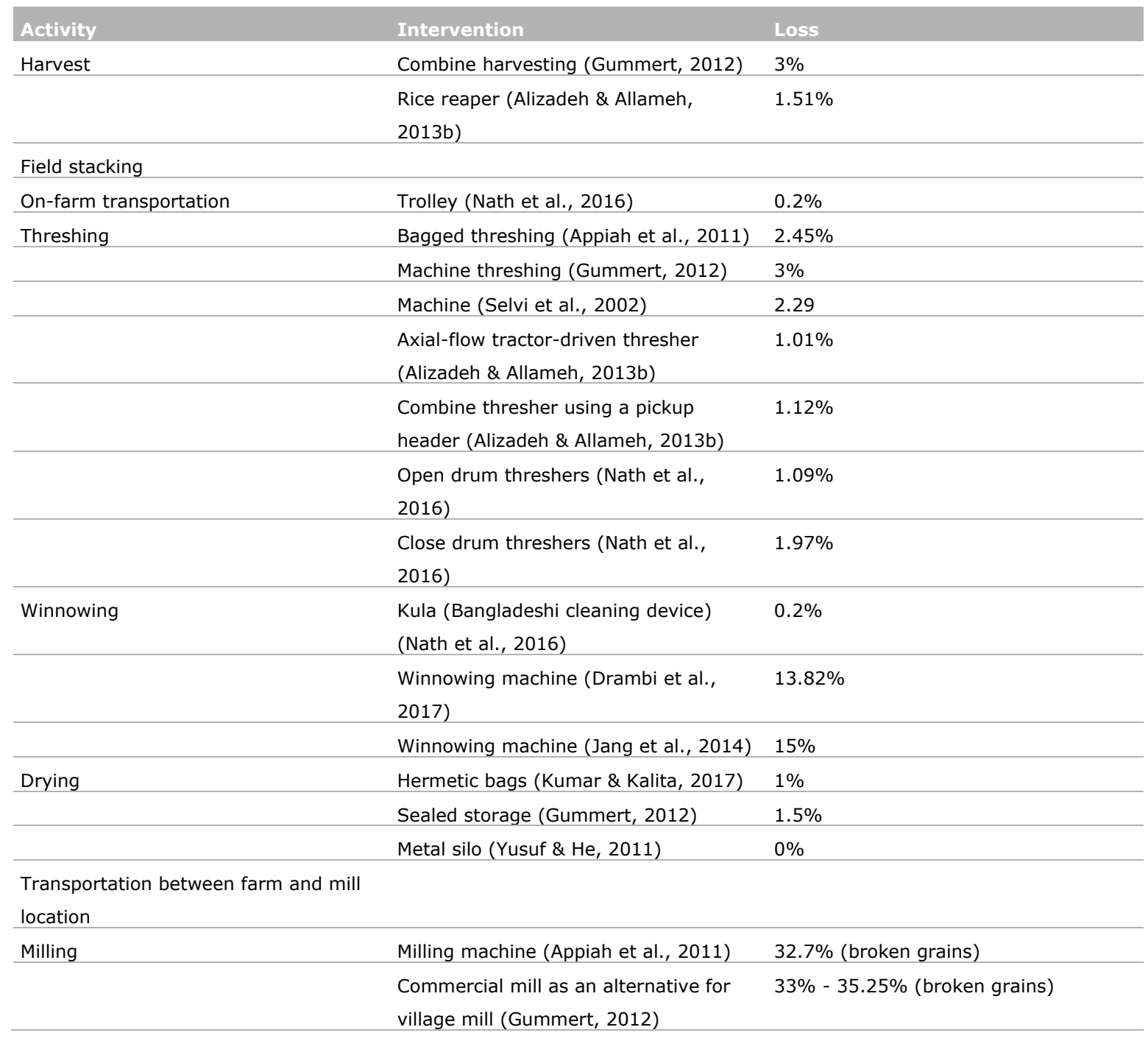

Above, in the loss profile compiled using studies reporting losses for rice chains with traditional methods and practices, losses in the rice chain were estimated to be between $9.9 \%$ in the best-case scenario and $47.69 \%$ in the worst-case scenario. This can be compared with measured losses of around $35 \%$ in smallholder Nigerian rice systems. Assuming the best possible scenario with these interventions (and taking the average default value for activities for which no intervention was found), on-farm losses would amount to $5.76 \%$, which is a considerable improvement, even compared to the very lower bound of loss estimates with default methods.

\subsection{Sesame}

Globally (in 2018), 6.448.961 tonnes of sesame seed were produced, primarily in Sudan (15.2\%), Myanmar (11.9\%), India (11.6\%), Nigeria (8.9\%), and Tanzania (8.7\%). Two of the reviewed publications were focused on one of these major producers, namely one in Myanmar (Myint et al., 2020) and one in India (Gharde et al., 2018). The majority of studies (5) were conducted in Ethiopia, which produces $4.7 \%$ of globally produced sesame, and three others in Bulgaria (Ishpekov et al., 2017; Ishpekov \& Stamatov, 2013, 2019). 


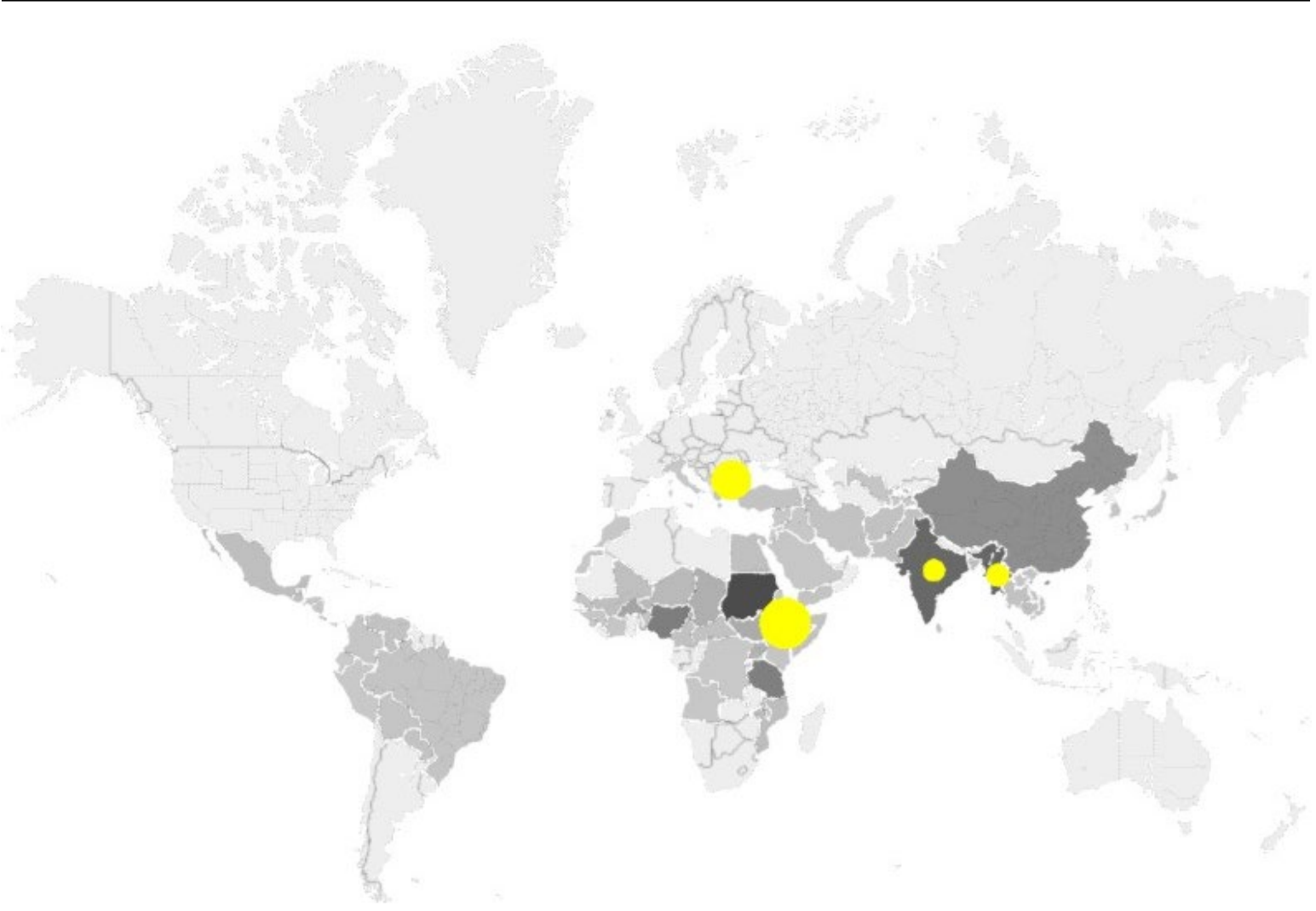

Figure 4 Countries' production of sesame seed (tonnes, grayscale shading) and country focus of studies reviewed (yellow). Source: FAO (2020).

Three studies cover losses along the entire chain (Abay \& Berhe, 2014; Desale et al., 2019; Kelali et al., 2014), providing a rather complete loss profile. However, these studies cannot be easily compared due to diverging definitions of activities, such as one study including losses due to harvest left on the field and others not. In terms of research context, Abay \& Berhe (2014) and Desale et al. (2019) focus on small farms, whereas Kelali et al. (2014) research a mix of small, intermediate, and large farmers, as well as investor farms. Also in terms of methods, there are considerable differences. Desale et al. (2019) and Kelali et al. (2014) both use a different mix of surveys of self-reported losses and sample measurements to estimate regional average losses. Abay and Berhe (2014) use a survey of farm households in three regions. All three studies with a more comprehensive loss profile report average loss rates without discerning differing regional factors and farmer's technologies and practices.

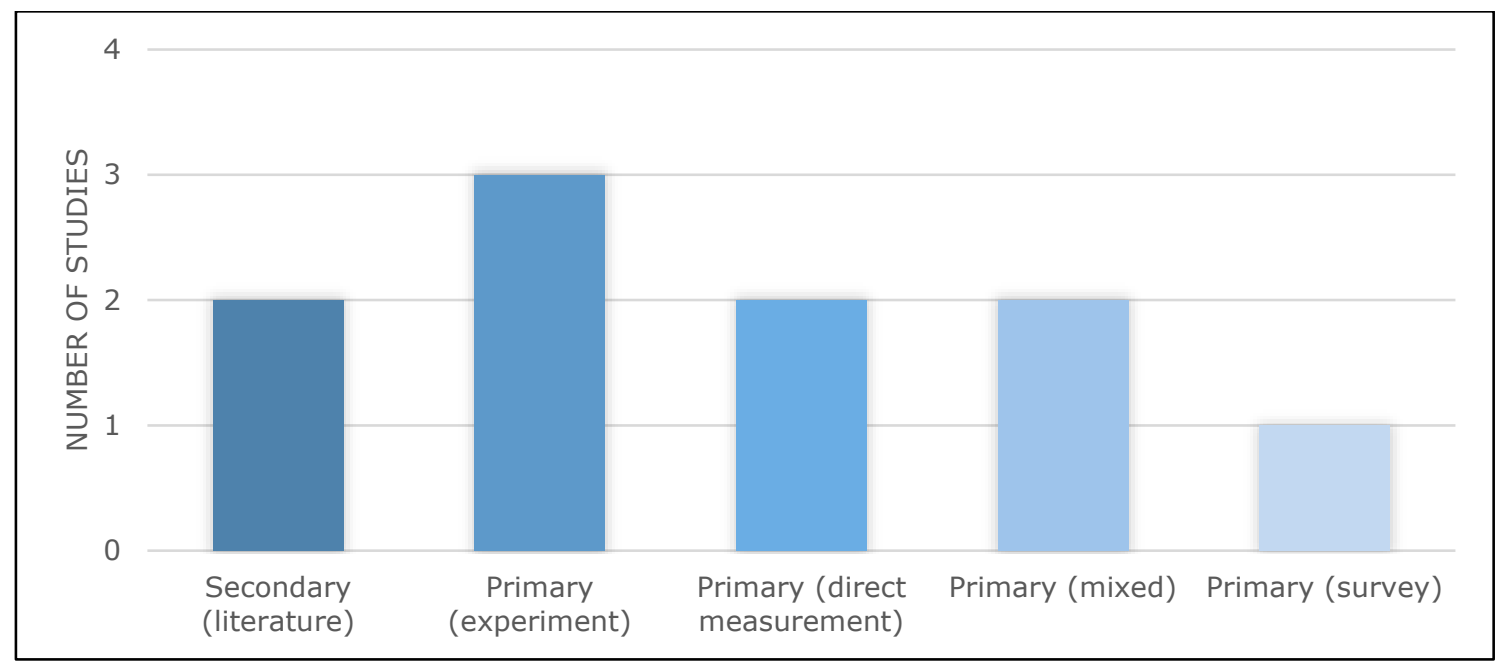

Figure $5 \quad$ Approaches used in reviewed studies (Sesame).

Other studies focus on (interventions targeting) one specific activity. Ishpekov et al. (2013, 2017) research specific harvesting and threshing technologies in experimental setups and report associated losses. Another of these focused studies (Berhe et al., 2011) reports losses for different on-farm 
storage methods, ranging from $97.4 \%$ loss for sesame seeds left in an open sack in the field outdoors to $0 \%$ for sesame seeds stored in a closed bottle in a laboratory setting. The most important practical conclusion is that replacing the open sacks with jute bags already reduces on-farm storage losses to $12,9 \%$, and replacing them with lined jute or polythene bags reduces losses to $0.6 \%$ and $0.3 \%$ respectively. Due to the wide range of losses for this one activity, these figures are not included in the figure below.

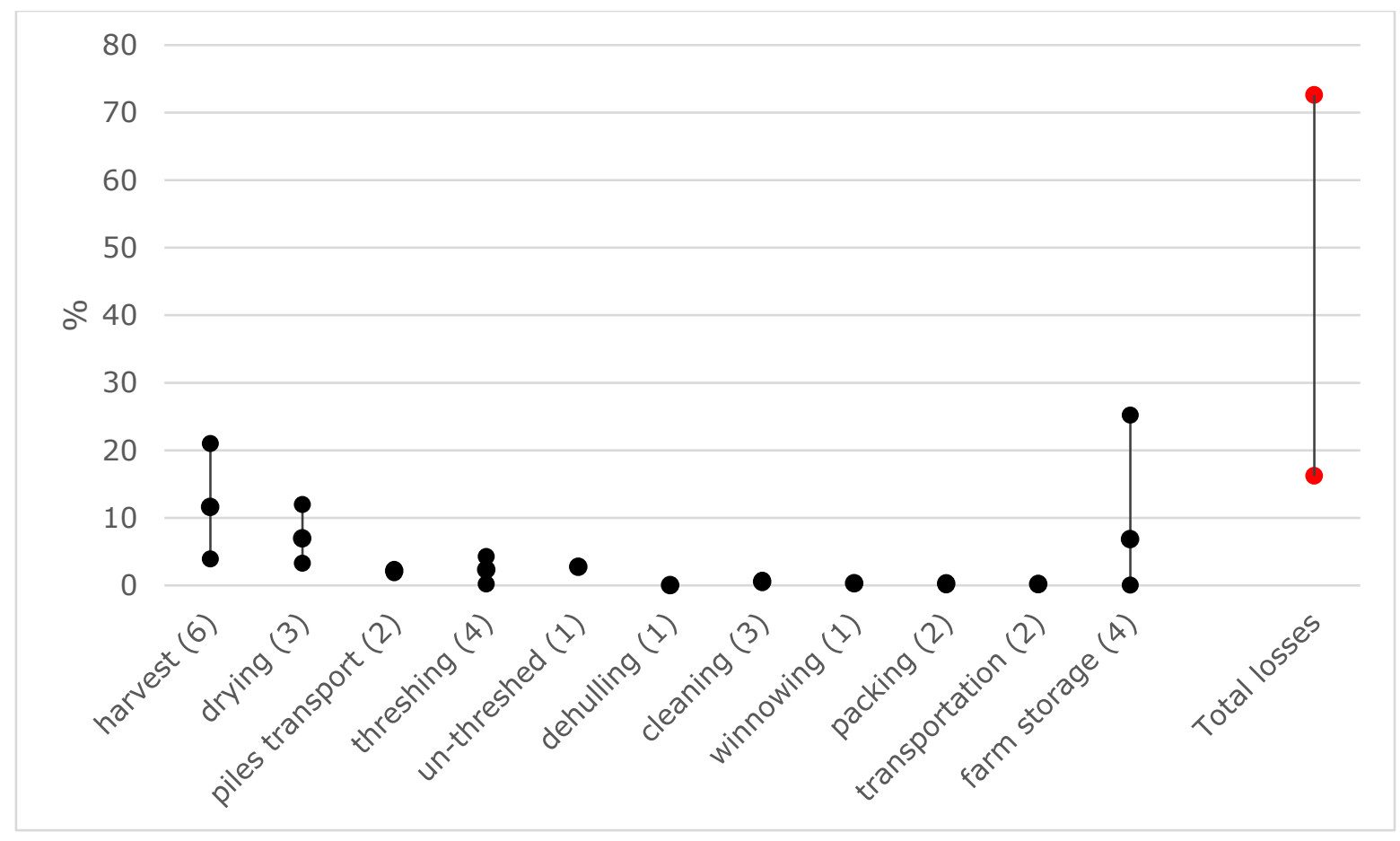

Figure 6 Sesame - Averages and range of product losses at chain activities, upper and lower bound of total losses. The number of loss estimates per activity indicated in parentheses.

The data for sesame is somewhat better than for most crops reviewed. Based on this overall loss profile from the literature, possible loss hotspots include harvesting, drying and farm storage (also considering the wide range of loss figures for different storage methods (Berhe et al., 2011)). However, activities with more loss estimates from different studies have a wide range of loss estimates, which accumulate to a rather wide range of estimated total post-harvest losses. Overall losses were quite high, considering the best-case scenario (least losses in each activity) of approximately $16 \%$. The upper estimate (approximately $75 \%$ loss) is surely excessive, assuming the worst practice at each stage - an unlikely outcome. Differences in definitions and methods make the studies challenging to compare, so conclusions beyond these roughly estimated upper and lower bounds are not feasible. Three studies also report total on-farm losses without a complete decomposition by activity. Numbers range from 13\% (Abay \& Berhe, 2014; Berhe et al., 2011) to $23.7 \%$ (Gharde et al., 2018), which are at the lower end of the estimated range.

The high potential losses in sesame and its importance for the livelihood of very poor farmers make it stand out amongst the studied crops as having good potential for post-harvest loss reduction efforts.

\subsection{Quinoa}

The global production of quinoa is 158.920 tonnes in 2018 (FAO, 2020). Peru accounts for 54.1\% of this production, Bolivia for another $44.3 \%$, and Ecuador for the remaining $1.4 \%$. The literature search identified five publications mentioning post-harvest losses of quinoa, three of which were based on studies conducted in Peru, and the other two on studies conducted in Bolivia. 


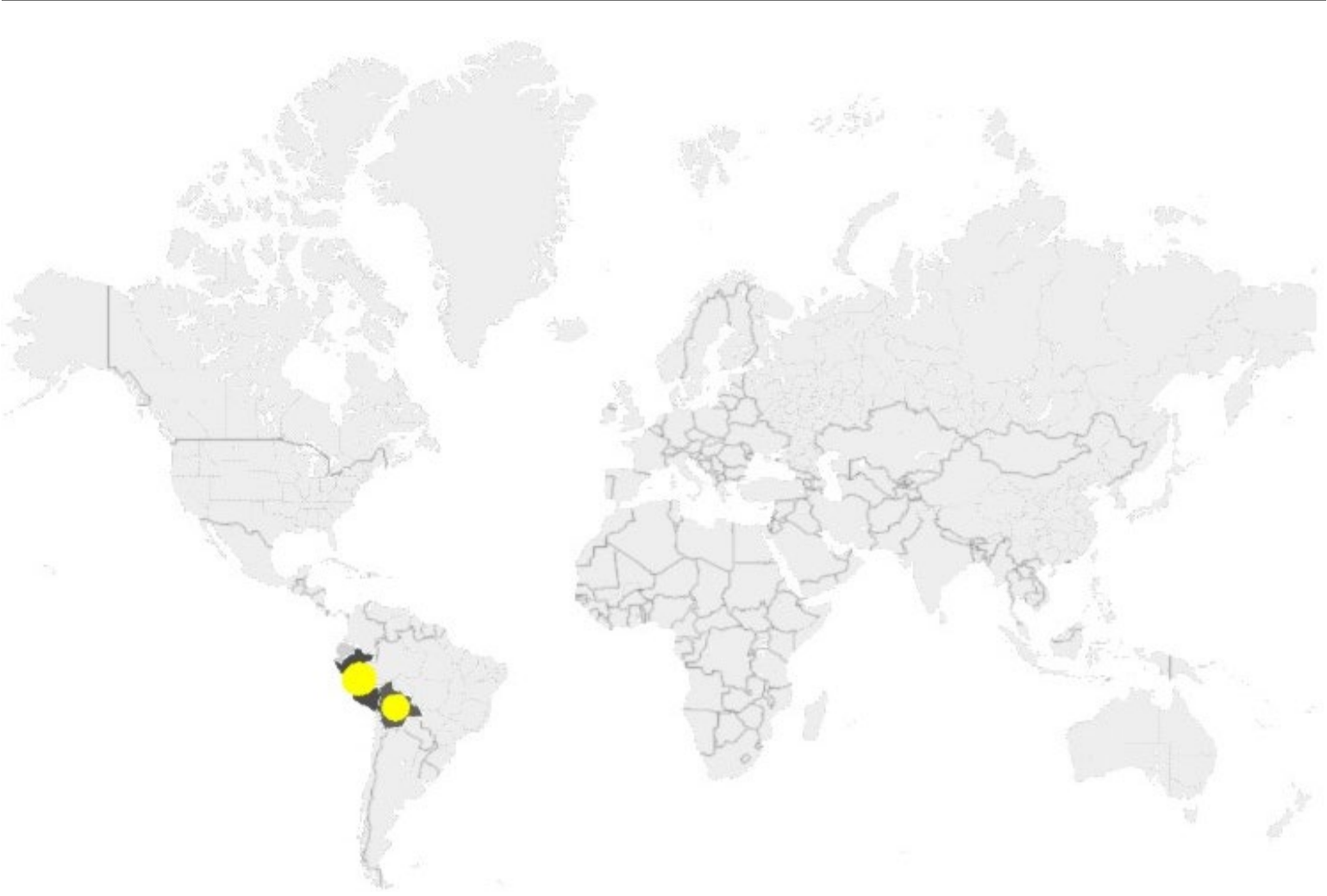

Figure 7 Countries' production of quinoa (tonnes, grayscale shading) and country focus of studies reviewed (yellow). Source: FAO (2020).

Of the studies reviewed, one study only provided estimates of pre-harvest yield losses due to downy mildew, which strongly depended on the region, variety, and severity of the problem (Danielsen \& Munk, 2004).

Salas Dominguez (2003) provides the most complete assessment of post-harvest losses (defined as weight loss as well as quality loss of the product) per activity, giving a range of loss values per activity, but base this entirely on estimates by De Lucia \& Assennato (1993) for postharvest losses in grains. Therefore the accuracy of these values for quinoa specifically is questionable. The relatively wide range of estimates for grain losses, in general, makes that these numbers are easier to generalize than others. Salas Dominguez does not report on the characteristics of farms growing quinoa.

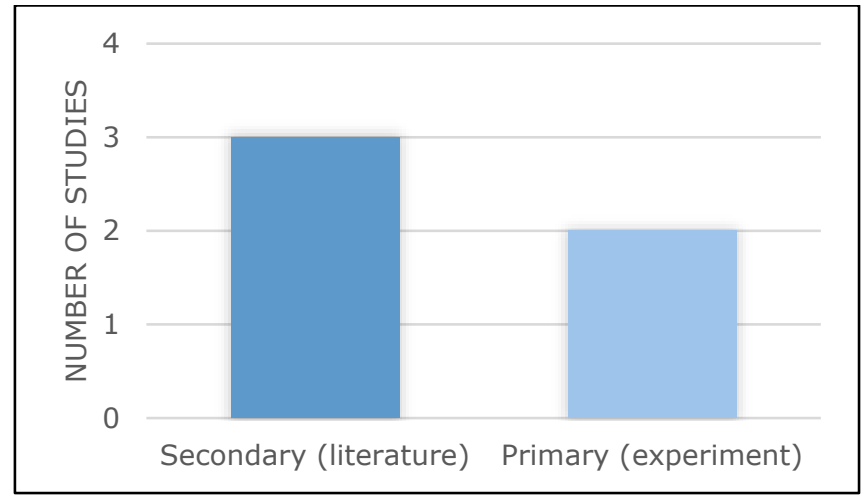

\section{Figure 8 Approaches used in reviewed studies (Quinoa).}

While Salas Dominguez reports figures for most relevant activities, the other studies focus on specific activities, such as sickle harvesting versus manual harvesting (Rojas et al., 2004), and traditional versus mechanical processing (Hayes, 2017; Quiroga et al., 2017; Rojas et al., 2004). These publications are based on experimental studies, producing primary measurement data, but often do not provide a definition of food loss (i.e. considering loss of volume and/or quality, and specifying the definition of when food is considered lost) and focus on only one activity. Findings from these studies 
are closely tied to specific use cases of (well described) technologies or practices, which may limit the generalizability of these figures. In this set of studies, there is no research that provides primary loss data along the entire chain. Therefore, the loss profile compiled should come with the caveat that the numbers included from different studies are not perfectly comparable. These studies were conducted among small-scale farms or larger cooperatives. The common trend among their findings indicates that the use of specific (harvesting or processing) equipment reduces post-harvest losses in these activities compared to 'standard' traditional practices.

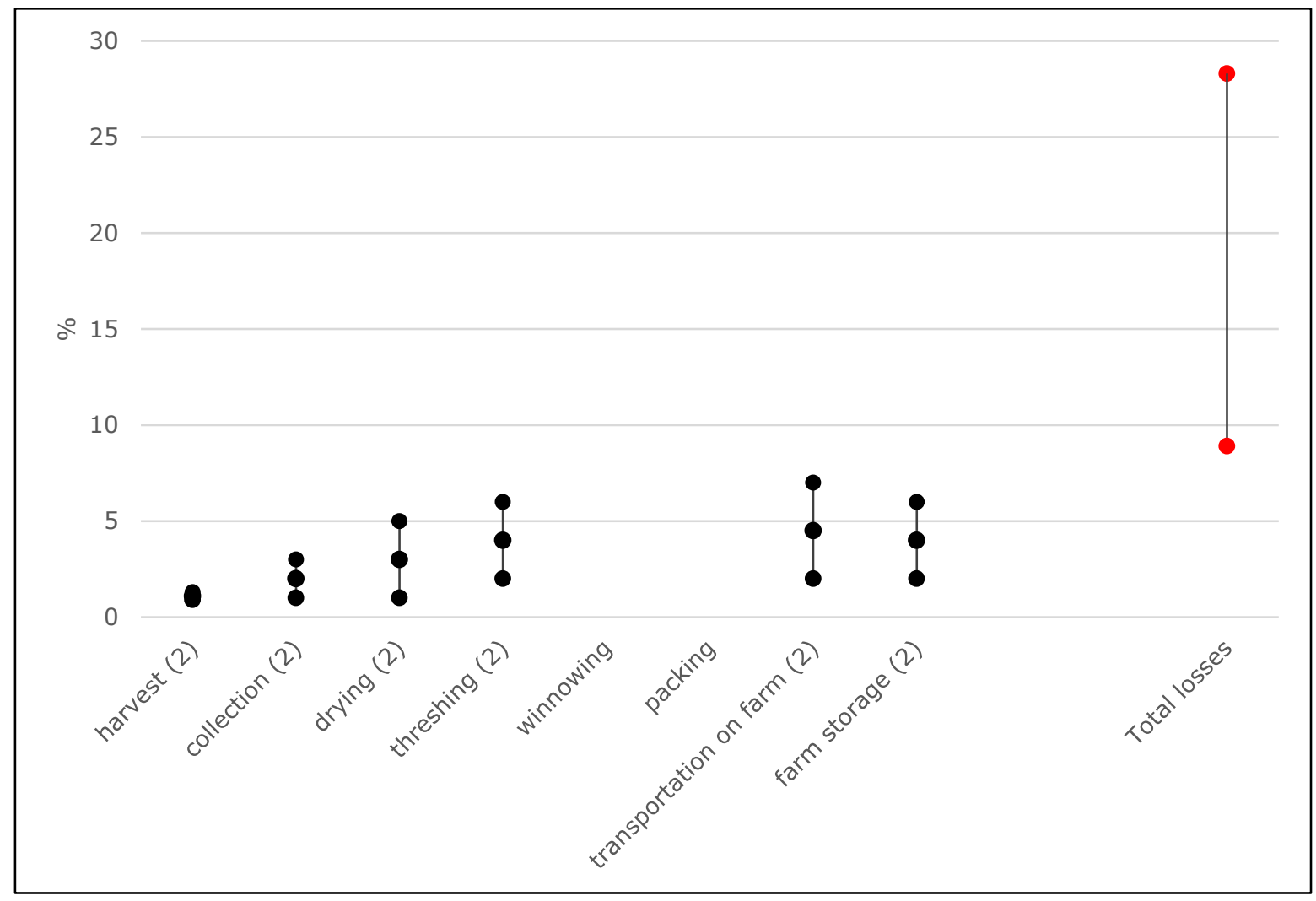

\section{Figure 9 Quinoa - Averages and range of product losses at chain activities, upper and lower bound of total post-harvest losses. The number of loss estimates per activity indicated in parentheses.}

Based on the information available from the studies, it is possible to compile a relatively comprehensive post-harvest loss profile for quinoa. Two studies that measure losses attributed to specific on-farm activities provide limited insight into the post-harvest loss profile for quinoa. Other studies that focus on processing (an activity out of scope for this study) report losses between 1 and $10.1 \%$, the difference occurring due to manual practices were replaced with mechanical processing. The lower and upper bounds of the on-farm loss estimates are attributed by these studies to traditional versus more modern practices and technologies. In addition to the studies that report specific numbers, Rojas et al. (2004) report total post-harvest losses of quinoa to be $24 \%$, and Hayes (2017) reports losses of $30 \%$, both without attributing this to specific activities. These numbers are at the top end of the total losses range estimated from the loss profile.

\subsection{Coffee}

Globally, in 2018 some 3.556.638 tonnes of coffee were produced, with $35.2 \%$ in Brazil, $15.5 \%$ in Vietnam, $6.9 \%$ in Indonesia, 6.9\% in Colombia, 4.6\% in Honduras, and $4.5 \%$ in Ethiopia. Compared to most other crops, a relatively large share of research is conducted in major producer countries, with 2 studies in Brazil, 1 in Colombia, and 1 in Ethiopia. In addition, the literature search yielded one study conducted in Papua New-Guinea and one in Tanzania. 


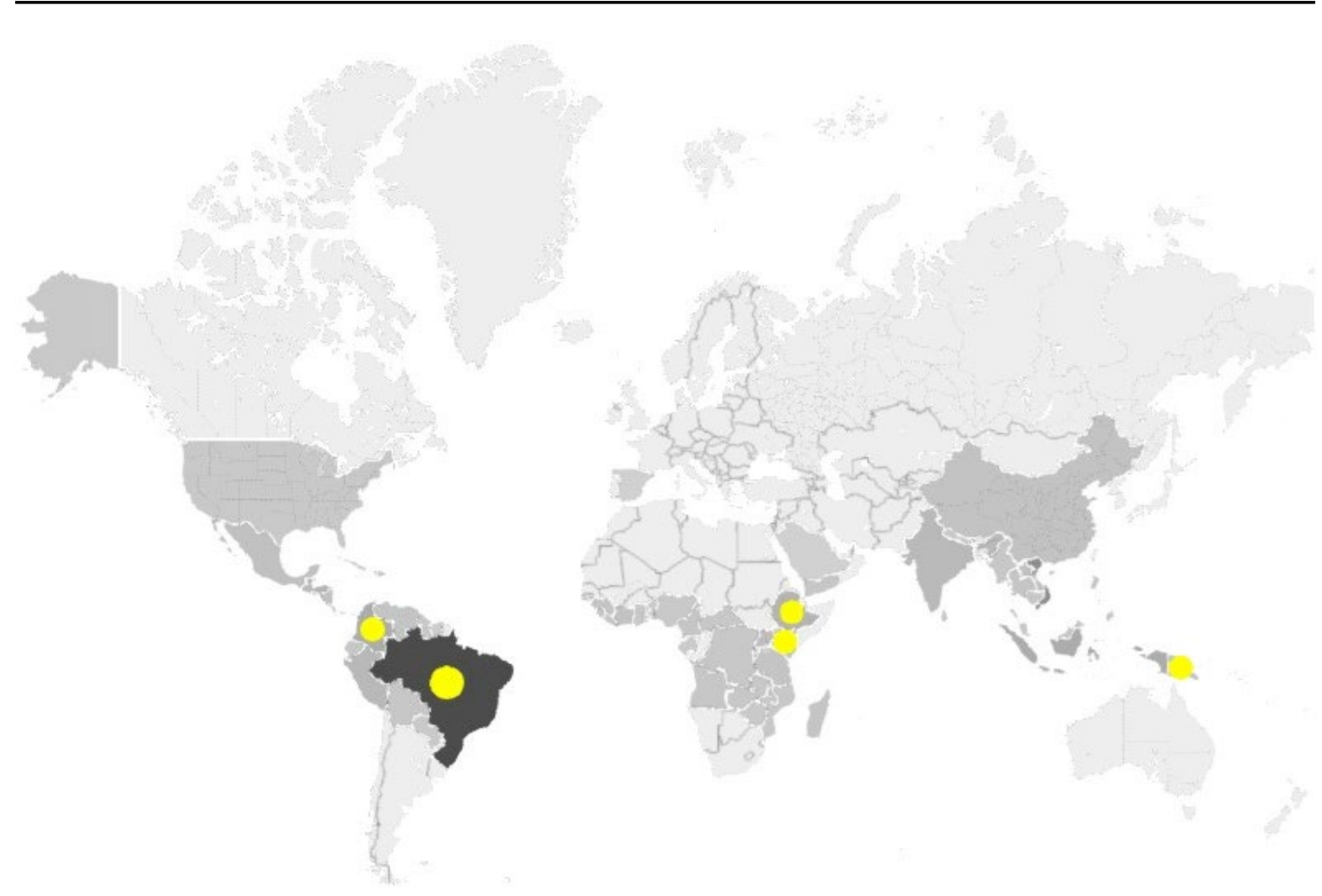

Figure 10 Countries' production of coffee (coffee, green) (tonnes, grayscale shading) and country focus of studies reviewed (yellow). Source: FAO (2020).

The great majority of studies is focused on preharvest threats such as pests and diseases (Avelino et al., 2018; Brook et al., 2015; Kasso \& Bekele, 2018; Oduor \& Simons, 2003; Otieno et al., 2019). The few studies that discuss losses attributed to specific post-harvest processes only report losses for one of these activities, producing an incomplete overall picture of losses and making it impossible to quantitatively compare studies.

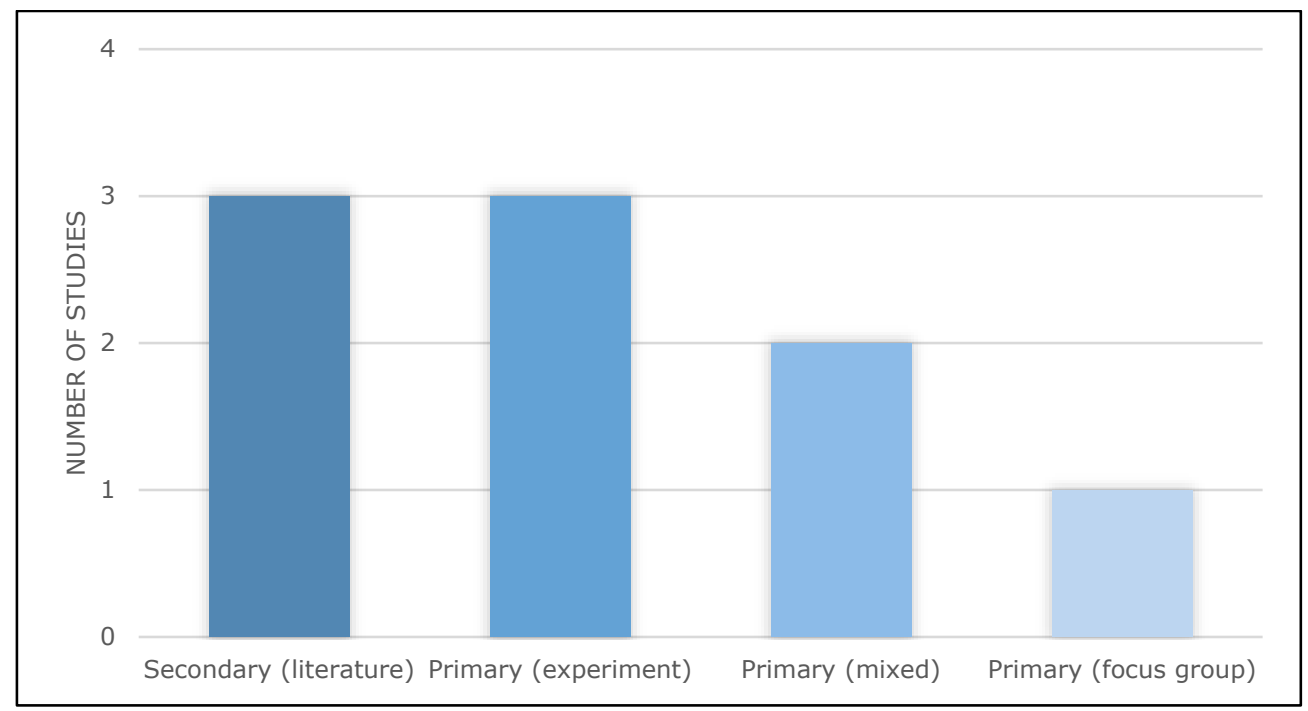

Figure 11 Approaches used in reviewed studies (Coffee)

When it comes to studies reporting post-harvest losses, De Carvalho Lopes and Steidle Neto (2020) report - based on experiments and quantitative modeling - losses between $0 \%$ and $1.2 \%$ of stored coffee beans, but do not specify what type of storage or storage location they considered. Another Brazilian experimental study (Abraao et al., 2018) reports coffee bean mass losses in a plantation setting between $0.5 \%$ and $6 \%$ due to fermentation. The last study that reports food loss in the coffee chain (Moreno Cárdenas et al., 2015) experimentally investigates the effectiveness of an electric harvesting device (used by plantation workers) in increasing yield and reducing losses due to bean 
damage, fruit left on the ground, and immature harvesting. The study shows that the use of the device improved yields (after a brief period of farmers learning to use it properly), but only measures and reports the magnitude of losses in the number of fruits per tree rather than volumes or percentages.

In sum, for coffee very limited information is available, prohibiting the identification of hotspots or estimation of the magnitude of post-harvest on-farm losses.

\subsection{Chillies and peppers}

In 2018, the world produced 54.985.494 tons of chillies and peppers (green) (FAO, 2020), of which China produced $33.1 \%$, followed by Mexico (6.1\%), Turkey (4.6\%) and Indonesia (4.6\%). 18 separate publications research losses in these chains (some publications reporting results from the same study), of which 12 focus on India, and one study each on Bangladesh, Indonesia, Ghana, Canada, Thailand, Laos, Vietnam and Rwanda (some publications focusing on more than 1 country). Strikingly, only one study focuses on one of the global top producer countries (Indonesia).

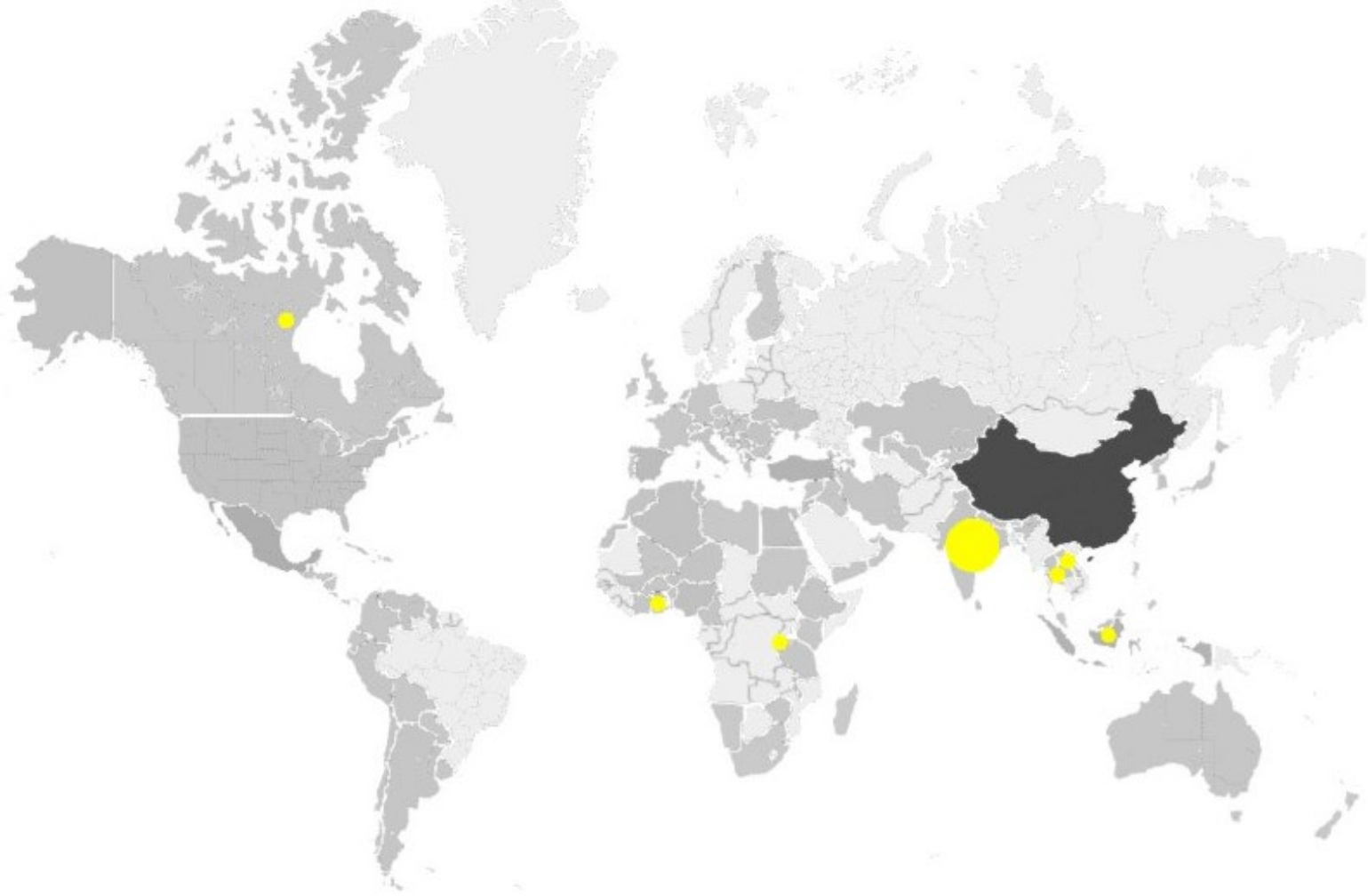

Figure 12 Countries' production of chilli peppers (chillies and peppers, green) (2018, tonnes, grayscale shading) and country focus of studies reviewed (yellow). Source: FAO (2020).

Despite the relatively large amount of publications, the information seems rather patchy. Most studies report where losses occur, without specifying the magnitude, reporting losses due to one cause only (e.g. powdery mildew (Cerkauskas et al., 1999; Sudheendra, 2005) or anthracnose (Islam et al., 2020; Schreinemachers et al., 2015)), or report the product loss after implementation of one specific intervention (e.g. Zero Energy Cool Chamber cold storage (Shil et al., 2018)). Often, the distinction is not made between fresh or dry chillies and peppers (only two studies report losses in the drying stage).

Of these studies, six provide loss percentages for more than one chain activity (Gauraha \& Thakur, 2008; Jha et al., 2015; Lalhmangaihchhungi, 2018; Mukantwali et al., 2018; Narayana et al., 2014; Sharma \& Singh, 2011). And only four studies (Jha et al., 2015; Lalhmangaihchhungi, 2018; Narayana et al., 2014; Sharma \& Singh, 2011), provide a somewhat comprehensive view of the full chain of 
activities between harvest of the fresh peppers and storage and marketing of dried peppers but use different definitions of activities. Overall, comparability seems to be limited. The definitions of activities differ considerably between studies - for example, some studies report certain losses in 'handling' and 'transport' separately (e.g. Lalhmangaihchhhungi (2018)) while others (e.g. Gauraha \& Thakur (2008); Sharma \& Singh (2011)) report these in one category 'handling and transport'.

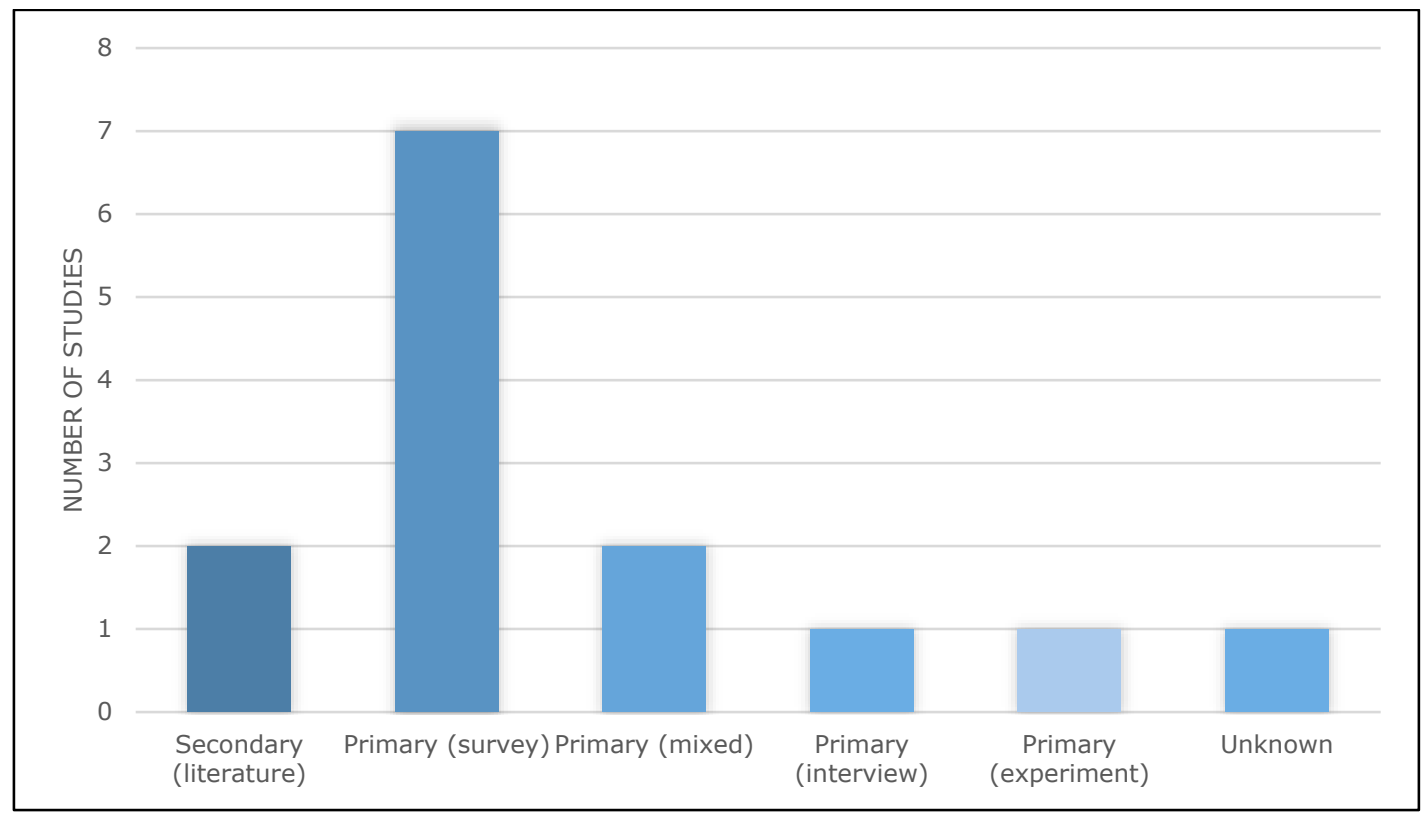

Figure 13 Approaches used in reviewed studies (Chilli peppers).

Also between those studies that quantify losses in at least one chain activity, definitions and measurements differ considerably. Some studies (e.g. Jha et al. (2015)) measure and report losses of product volume, whereas others (e.g. Mukantwali et al. (2018) report defects, decay, and mechanical damage for select activities. As shown above, $50 \%$ of the studies on chilli pepper are based on survey data. Between the studies that are most rich in loss quantifications, methodologies also differ considerably, with the majority of studies using physical measurements (Jha et al., 2015; Mukantwali et al., 2018; Narayana et al., 2014), and one relying on self-reported estimates (Lalhmangaihchhungi, 2018). The two studies discussed in the sections above (Jha et al., 2015; Narayana et al., 2014) report aggregated regional averages from a survey of farmers, whereas the other studies report in their method section to focus on individual farmers or growers, rather than larger plantations. One study reports on a mix of small- and medium-sized farms, as well as larger coops (Mukantwali et al., 2018).

All of the above complicates comparisons between studies. To at least give a rough indication of loss incidence along the chilli pepper chain, reported figures are combined in the figure below - of course acknowledging the flaws in this comparison. To report loss percentages, overlapping activities are combined into one discrete activity. 


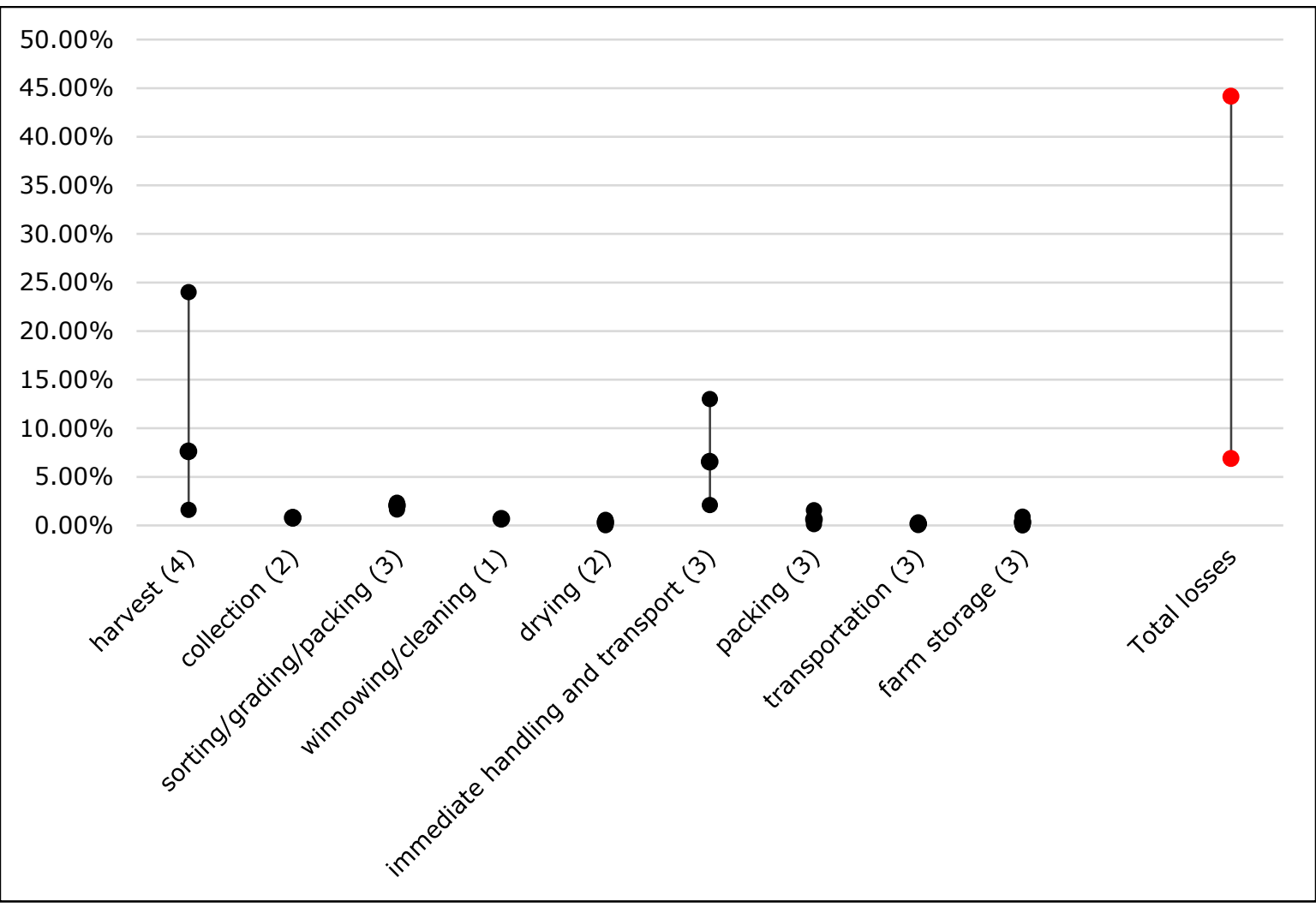

Figure 14 Chillies and peppers - Averages and range of product losses at chain activities, upper and lower bound of total losses in farm operations. The number of loss estimates per activity indicated in parentheses.

The wide range of loss values reported for harvest and immediate handling and transport are for an important part due to Mukantwali et al. (2018) reporting $24 \%$ of harvest suffering from mechanical damage, and $13 \%$ weight loss in immediate handling and transport. Losses in other individual processes are low (<2.5\%) and cumulative loss from all 'best case' scenarios combined is also modest (approximately 7\%). However, the overall problems of comparisons between studies prevents us from drawing certain conclusions. Specific studies report total on-farm losses of $4.73 \%$ (Narayana et al., 2014), 5.12\% (Jha et al., 2015), 9.89\% (Sharma \& Singh, 2011) and 16.3-20\% (Osei-Kwarteng et al., 2012), all of which are at the lower end of the total losses estimated from the loss profile, suggesting that the upper bound estimate (worst case scenario) is strongly driven by outliers.

\subsection{Black pepper}

World production of black pepper (768.868 tonnes in 2018 (FAO, 2020)) is strongly dominated by Vietnam (34.1\% of world production) followed by Brazil (13.2\%), Indonesia (12.6\%) and India $(8.8 \%)$. Existing research of losses in black pepper chains is mostly focused on India with 5 studies (Jahagirdar \& Siddaramaiah, 2000; Jha et al., 2015; Narayana et al., 2014; Ramana et al., 1994; Ravindra et al., 2014). In addition, one study investigates black pepper product losses in Brazil (Veronica et al., 2016). No studies were found that were conducted in the world's largest producer country (Vietnam). 


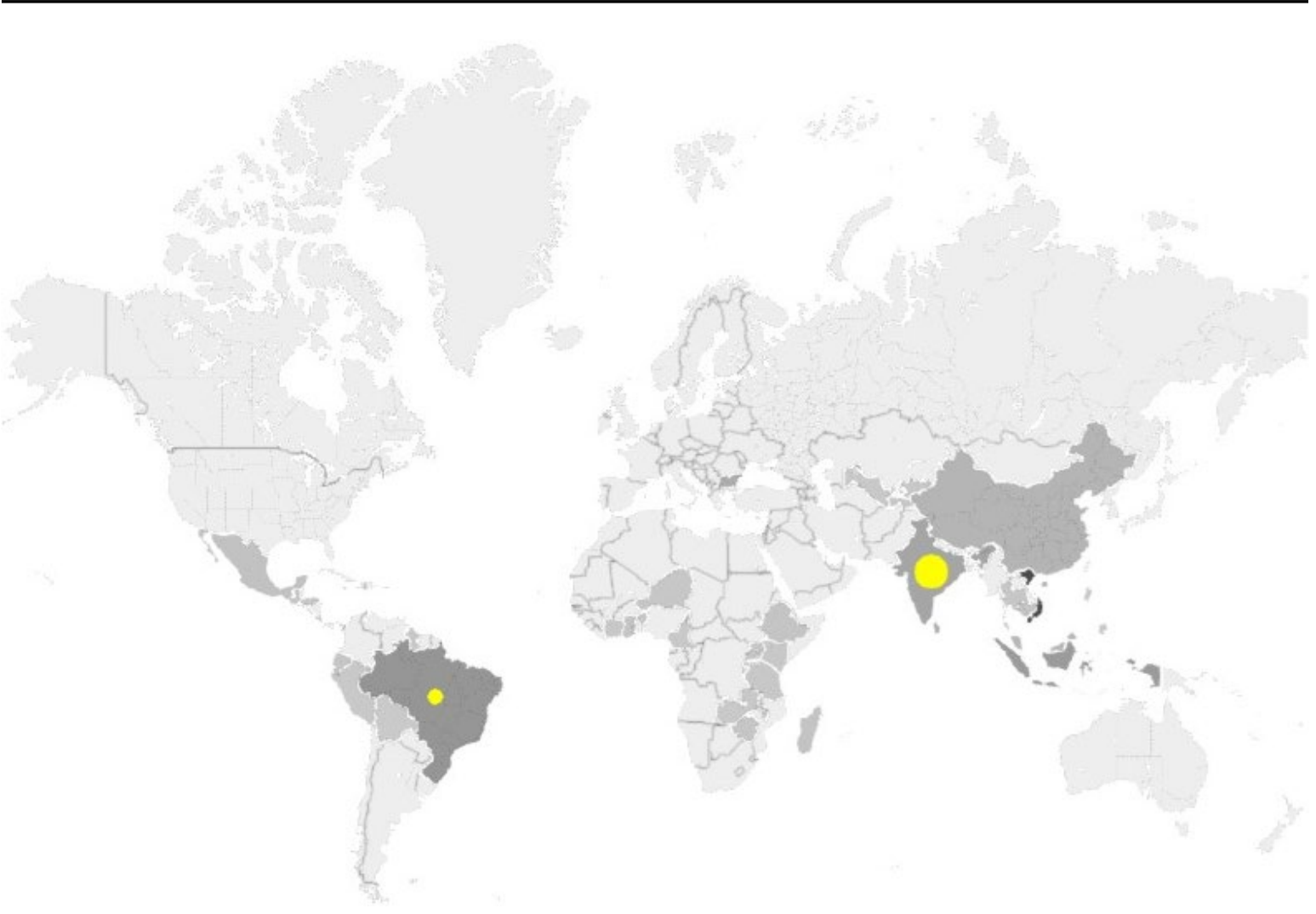

Figure 15 Countries' production of pepper (piper spp.) (2018, tonnes, grayscale shading) and country focus of studies reviewed (yellow). Source: FAO (2020).

A significant share of research focuses on losses related to one specific cause, for example, foot rot causing a $3 \%$ reduction in cultivated area and production of Brazilian black pepper (a pre-harvest loss cause) (Veronica et al., 2016), incidences of slow decline disease cause crop losses of $32 \%$ in Indonesia and 30\% in Guyana, and nematodes can cause yield reductions of 30.5-64.4\% (Ramana et al., 1994; Ravindra et al., 2014). These studies all report findings from others studies, which were hard to trade back or verify. The study by Jahagird and Siddaramaiah (2014) does report primary data from an experiment, but focuses only on pre-harvest losses. The other two (survey-based) studies focus on the postharvest chain in a more integrated way (Jha et al., 2015; Narayana et al., 2014).

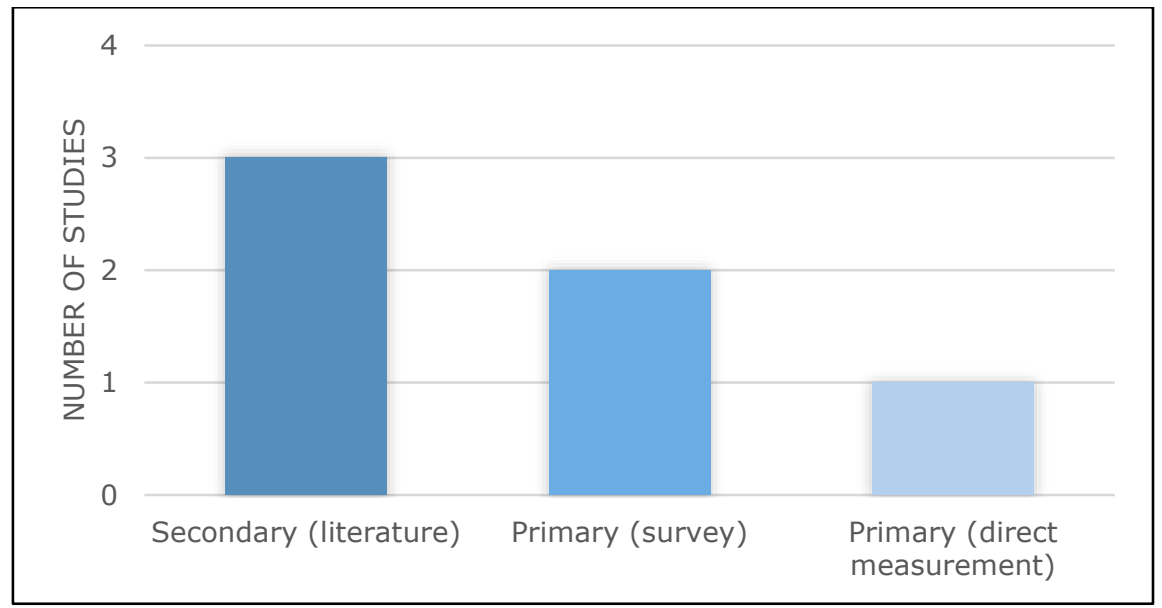

Figure 16 Approach used in reviewed studies (Black pepper).

Most studies do not provide an explicit definition of food loss. A large share of studies that research black pepper focus only on pre-harvest losses (Ramana et al., 1994; Ravindra et al., 2014; Veronica et al., 2016). The destination of lost produce (left on field, animal feed, etc.) is not specified in any study. The studies reviewed on black pepper all use physical measurement (sampling) to quantify losses. The only two studies that quantify losses along successive chain activities (Jha et al., 2015; Narayana et al., 2014) specify the protocol of loss measurement for the farmers participating in the 
survey (e.g. threshing $5 \mathrm{~kg}$ of unthreshed produce) but report regional averages regardless of farm size (distinguishing smallholders from larger farm operations) and the practices and techniques of individual farms where measurements are done. Therefore, the causes of losses and appropriate interventions are difficult to specify.

The extent to which the studies on black pepper are generalizable and comparable is limited. The two studies that provide a comprehensive evaluation of losses by activity base this on regional averages without accounting for differences between regions or farms. For a rough estimate of losses along the chain, this approach is useful, however. Based on these two studies, losses in farm operations in these Indian regions can be expected to be between 1\% (Jha et al., 2015) and 3.9\% (Narayana et al., 2014). Jahagirdar and Siddaramaiah (2000) quote values of $3.7 \%$ and $9.4 \%$ of total postharvest losses for Calicut and Cannanore respectively, without reference to how losses were measured or estimated. Specific loss estimates by chain activity are shown below, from those studies that report specific loss figures for activities.

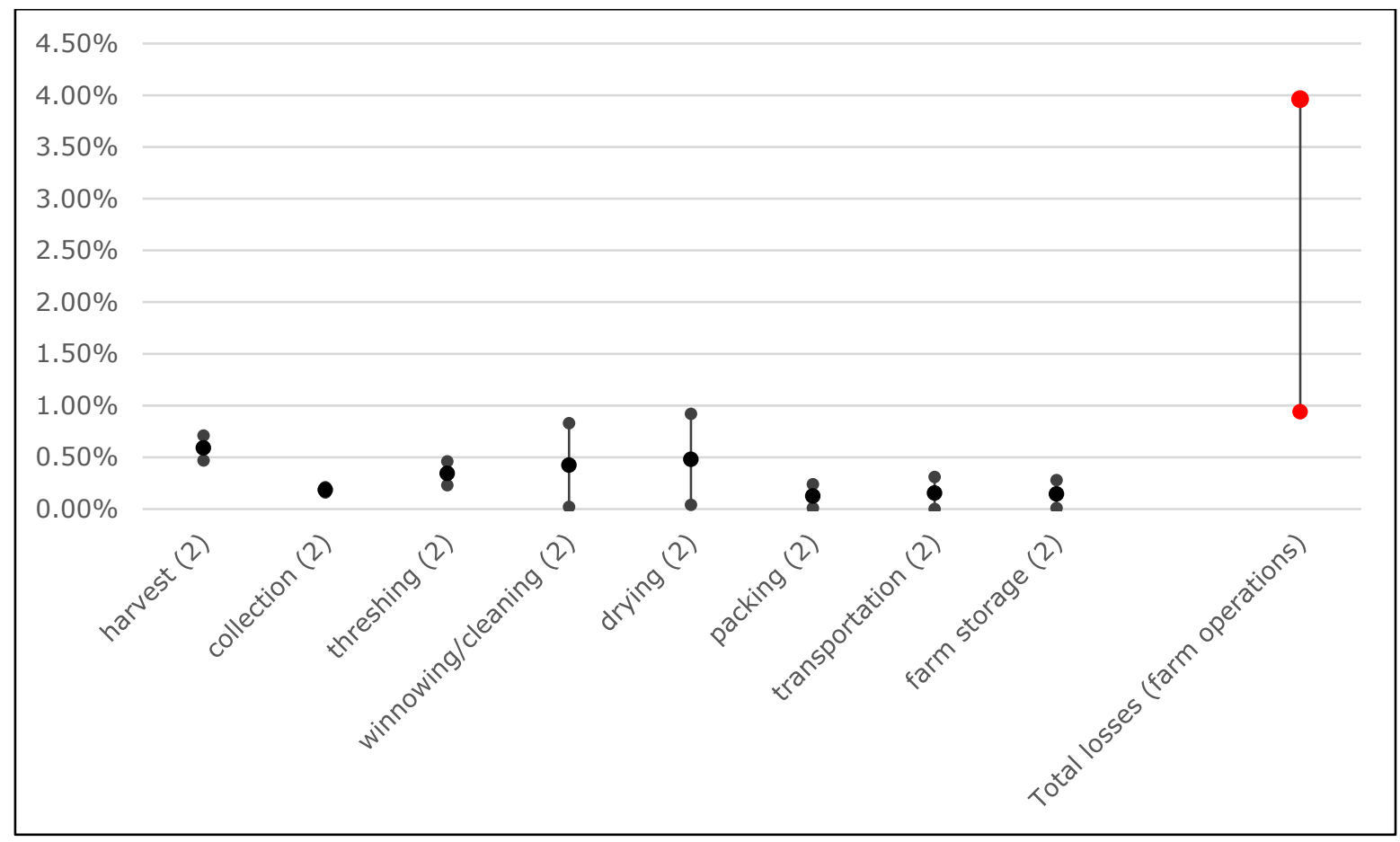

Figure 17 Black pepper - Averages and range of product losses at chain activities, upper and lower bounds of total losses in farm operations. The number of specific loss figures per activity indicated in parentheses.

Ideally, such an exercise should give a rough indication of where food loss hotspots are (with relatively higher losses than other activities). The winnowing/cleaning and drying stages show the highest maximum values in this limited survey. When considering the average values, the harvesting stage may be the most relevant hotspot, even though overall postharvest losses seem to be limited.

In sum, two studies provide values for product losses in different stages of black pepper postharvest chains, both based in India (a significant producer country, but not the largest). Total reported postharvest losses are low in the selected black pepper farming systems and may be highest in harvesting (picking), winnowing, and drying, but the data is too sparse to identify hotspots with certainty.

\subsection{Cashew}

The global production of cashew nuts (5.932.730 tonnes in 2018 (FAO, 2020)) is also strongly concentrated in Vietnam (44.9\% of global production), with other large producers being India (13.2\%) and Cote d'Ivoire (11.6\%). Of the four studies found reporting post-harvest losses of cashew, two 
focus on India (Jha et al., 2015; Narayana et al., 2014), one on Sri Lanka (Priyashantha et al., 2020), and one on Nigeria (Adeigbe et al., 2015).

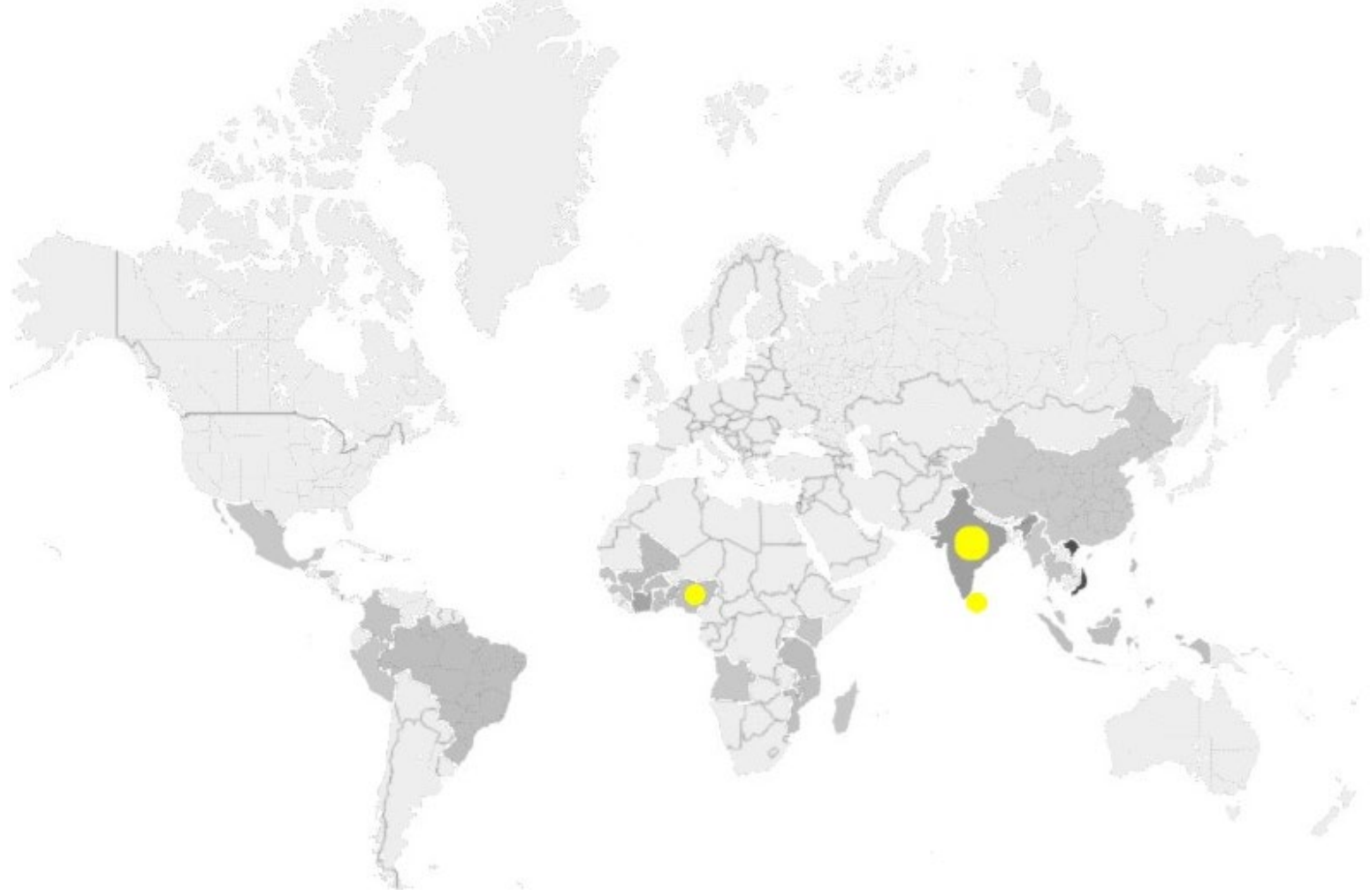

Figure 18 Countries' production of cashew (cashew nuts, with shell) (2018, tonnes, grayscale shading) and country focus of studies reviewed (yellow). Source: FAO (2020).

The two survey-based studies focusing on India are the only studies reporting losses per activity and total losses (Jha et al., 2015; Narayana et al., 2014). Priyashantha et al. (2020) also reports results from a conducted survey, but in terms of food losses only report that unexpected rainfall caused a $25 \%$ weight loss, not specified where it happened in the chain. Adeigbe et al. (2015) report yield losses of up to $54.8 \%$ due to Analeptes trifaciata infestation (the Cashew Stem Girdler, a beetle causing pre-harvest losses) and losses of up to $40 \%$ due to the harvesting of cashew apples without regard for the maturity of the fruit - all from previous literature, which could not be traced.

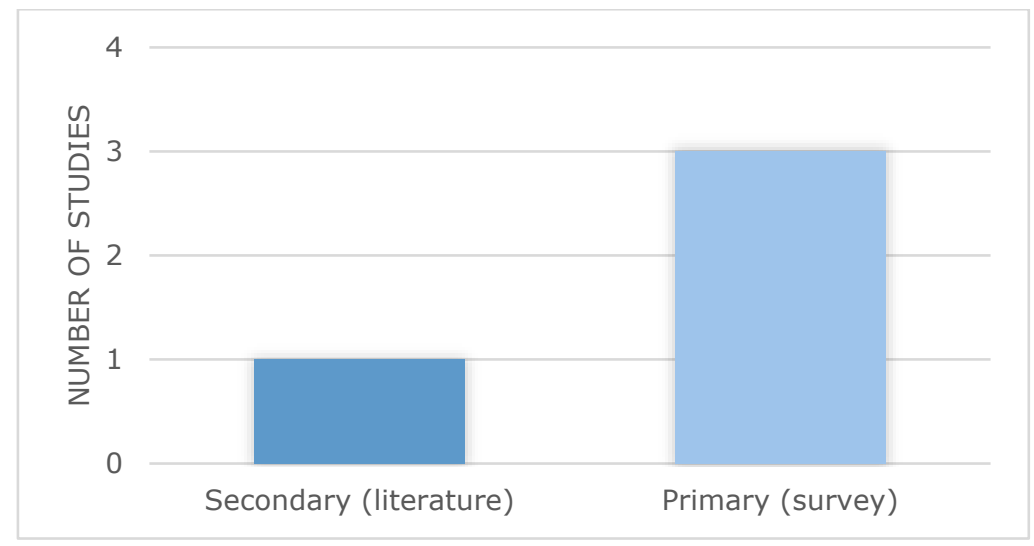

Figure 19 Approach used in reviewed studies (Cashew).

The two Indian studies report - as described above - regional averages of losses, as measured through physical measurements on farms. Differences between farms and effects of farm- and regionspecific factors are not reported or discussed. Again, for a rough estimate of total losses and relevant hotspots, these broad-scope studies are useful. Specific loss estimates by activity are shown below. 


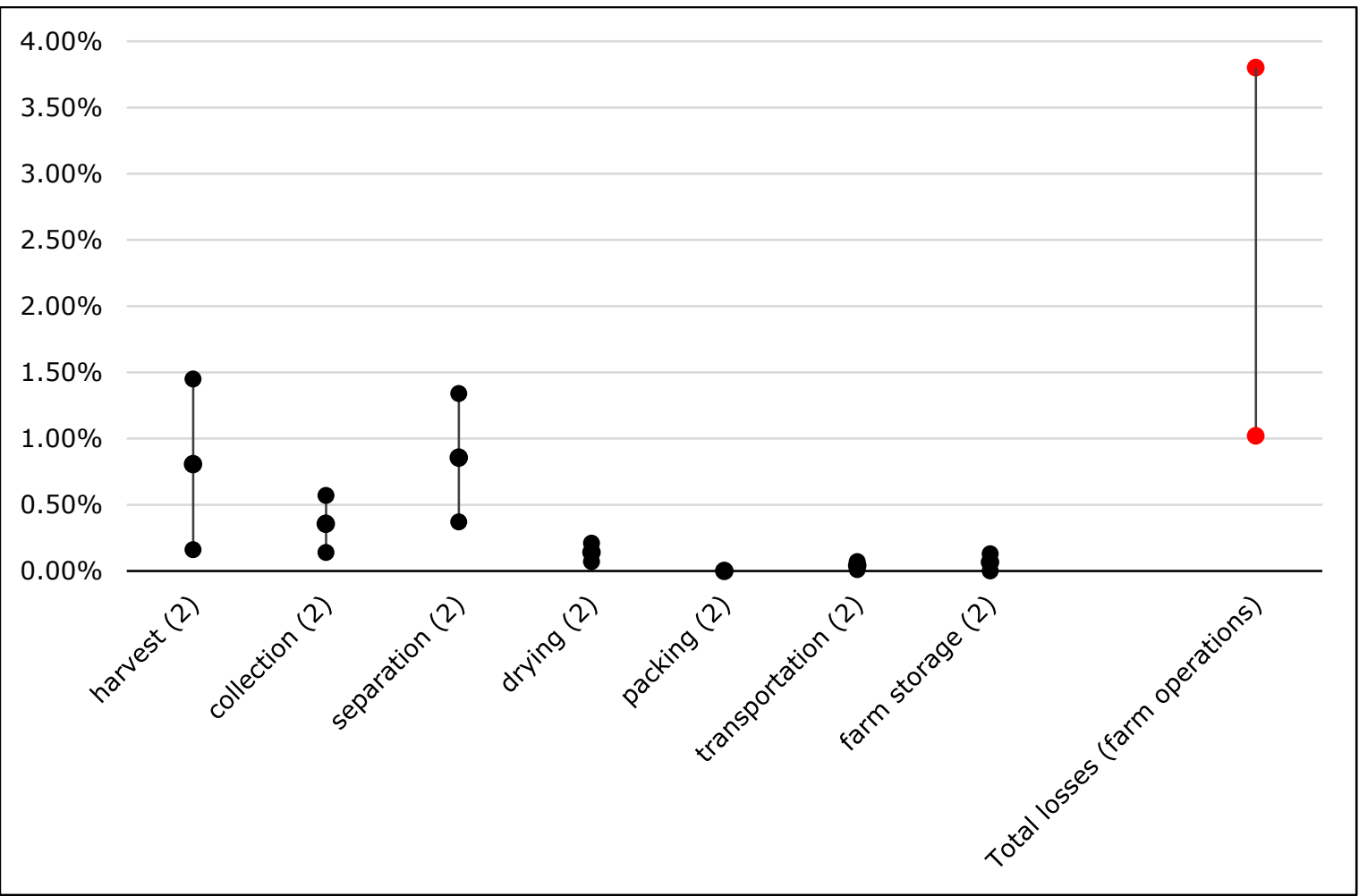

Figure 20 Cashew - Averages and range of product losses at chain activities, upper and lower bound of total losses in farm operations. The number of loss estimates per activity indicated in parentheses.

The total product losses in farm operations range from $1.02 \%$ (assuming the least losses in all activities) to $3.8 \%$ (assuming the most losses in all activities). Other than for the case of black pepper considered above, the overview of loss values per activity in the cashew chain gives a good indication that the loss hotspots occur early in the chain, with relatively higher average losses in harvest and cutting/cleaning. After separation of the nut from the apple, losses seem to be minimal based on the data. It remains uncertain how these figures translate to production contexts outside of the Indian regions where the studies were conducted. The data does not reflect the problem of improper drying, which starts on-farm but can cause rotting and consequent losses further on in the chain (GrosseRuschkamp \& Seelige, 2010).

\subsection{Hazelnut}

Of the global hazelnut production (888.678 tonnes in 2018 (FAO, 2020)), 58\% is concentrated in Turkey, with Italy (14.9\%), Azerbaijan (5.9\%) and the United States (5.2\%) being the other main producers. Research on post-harvest losses of hazelnut is - like for other smaller crop categories in this study - very limited. The literature search yielded two studies conducted in the world's top producer (Turkey) (Beyhan et al., 2009; De Wit, 2014). Other studies were conducted in Poland (Markuszewski \& Kopytowski, 2015) and Georgia (Shavgulidze \& Zvyagintsev, 2017), and another reporting on general pest management for hazelnut crops (USAID, n.d.). Two studies focus specifically on small scale farms (De Wit, 2014; Shavgulidze \& Zvyagintsev, 2017), the others do not discuss the farm context, but are inferred to focus on smallholder farmers due to the country context. 


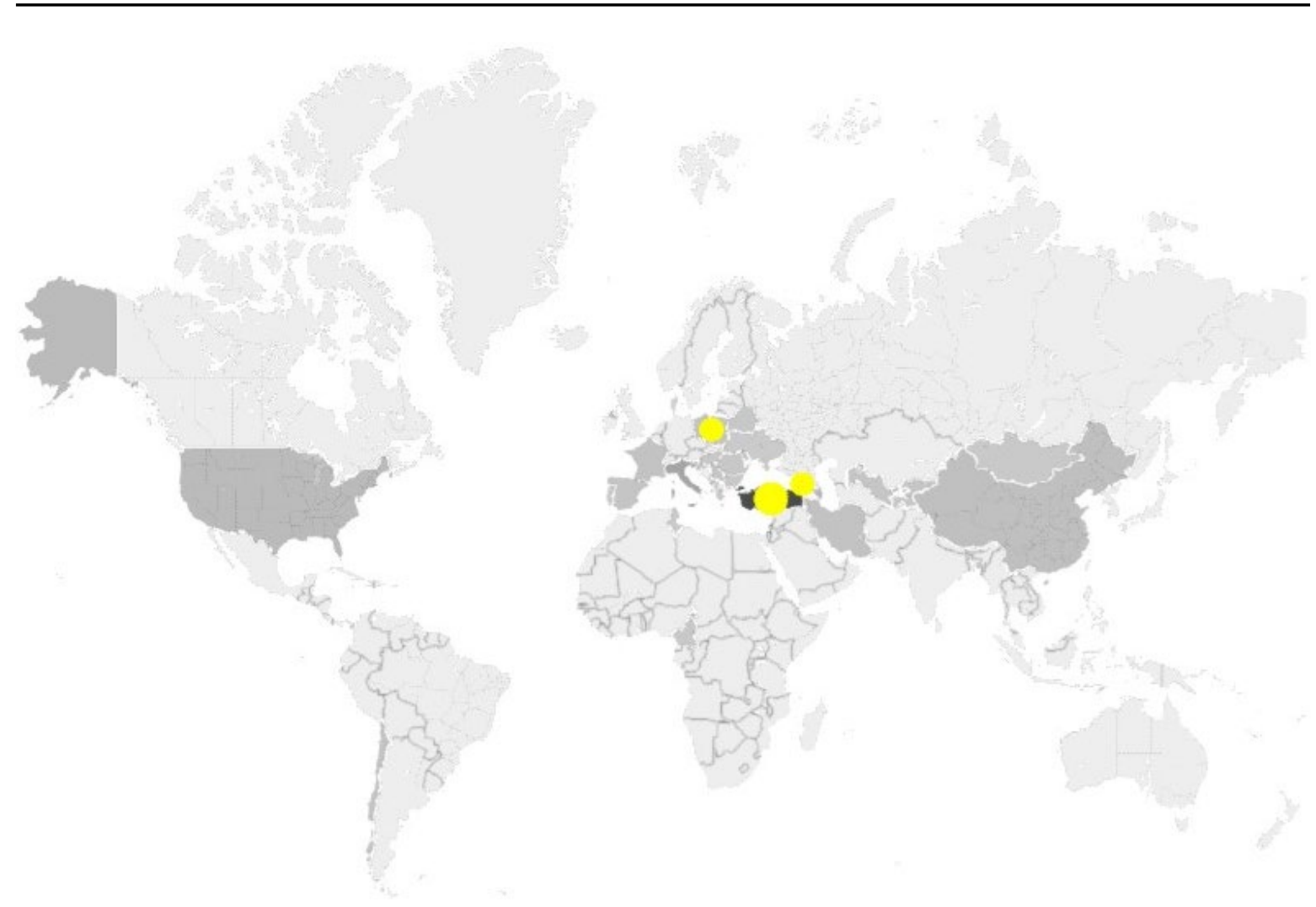

Figure 21 Countries' production of hazelnut (hazelnuts, with shell) (tonnes, grayscale shading) and country focus of studies reviewed (yellow). Source: FAO (2020).

The five studies reviewed only offer some scattered estimates of losses per activity. One experimental study reports measured weight losses in storage ranging from $9 \%$ (modified atmosphere bags) and $36 \%$ (standard cold storage) (Markuszewski \& Kopytowski, 2015). Another experimental study observed kernel losses during de-husking between $0.1 \%$ and $2.78 \%$ and nut damage between $0 \%$ and $3.49 \%$ (Beyhan et al., 2009). USAID (n.d.) provides a global overview of issues in hazelnut production, but does not refer to specific sources. De Wit (2014) and Shavgulidze and Zvyagintsev (2017) conduct interview and survey studies of hazelnut farmers in Turkey and Georgia respectively, but loss estimates are very limited (identifying that losses are taking place, rather than how much). Overall as for the case of coffee beans above, it is not possible to estimate a full post-harvest loss profile (or formulate upper and lower bound estimates of total on-farm losses) for hazelnuts due to the absence of loss estimates for most post-harvest activities.

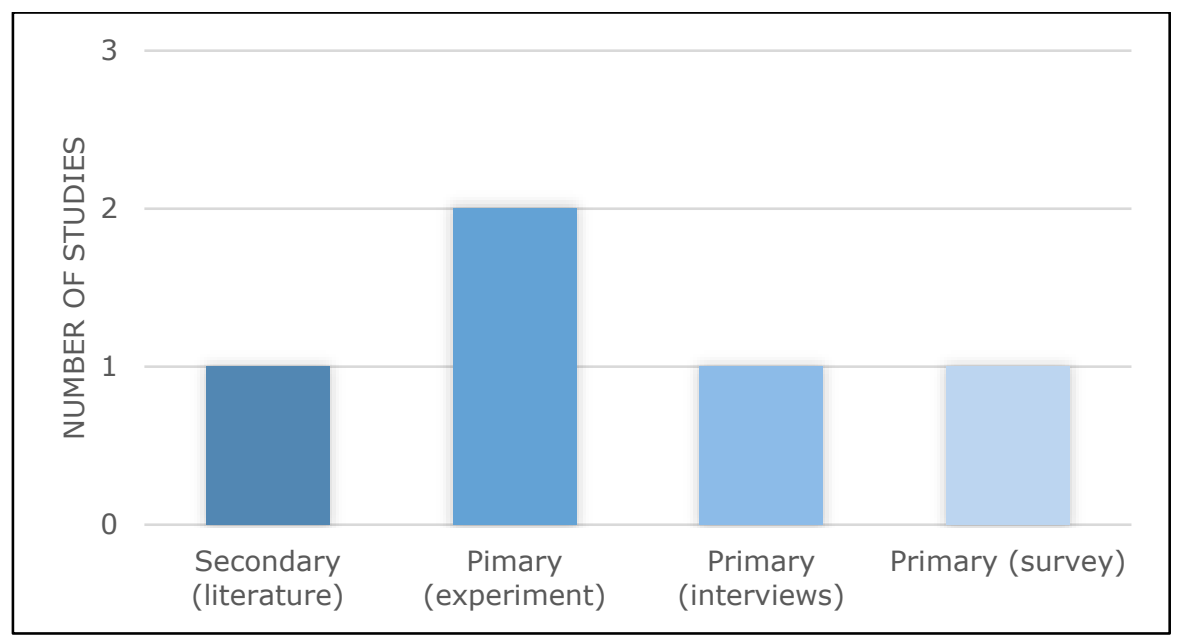

Figure 22 Approaches used in reviewed studies (Hazelnut). 


\subsection{Cocoa}

Most of the world's cocoa (5.252.376 tonnes in 2018 (FAO, 2020)) is produced in Cote d'Ivoire $(37.4 \%)$, Ghana $(18 \%)$, and Indonesia (11.3\%). The literature search yielded four studies reporting on postharvest losses of cocoa, focusing on West Africa (Cote D'Ivoire, Ghana, Nigeria, Cameroon) (Wessel \& Quist-Wessel, 2015), Samoa (Asora-Finau et al., 2018), Vietnam (Nguyen et al., 2019) and Malaysia (Zulkarnain et al., 2020). Of these studies, only Wessel \& Quist-Wessel (2015) focus on a major cocoa producing region, with the other three focus countries producing far smaller amounts.

Figure 23 Countries' production of cocoa (cocoa, beans) (tonnes, grayscale shading) and country focus of studies reviewed (red). Source: FAO (2020).

The data on cocoa product losses is very limited. No study reports loss values for several activities. Wessel and Quint-Wessel (2015) give, based on a literature study, an overview of individual causes of crop loss, mostly pests and diseases, that can lead to pre-harvest crop losses of $25-40 \%$ (measured by pods lost), depending on the nature and severity of the problem. The other three studies are experimental studies focusing on one specific activity (fermentation (Asora-Finau et al., 2018), breaking/winnowing (Nguyen et al., 2019), and drying (Zulkarnain et al., 2020).

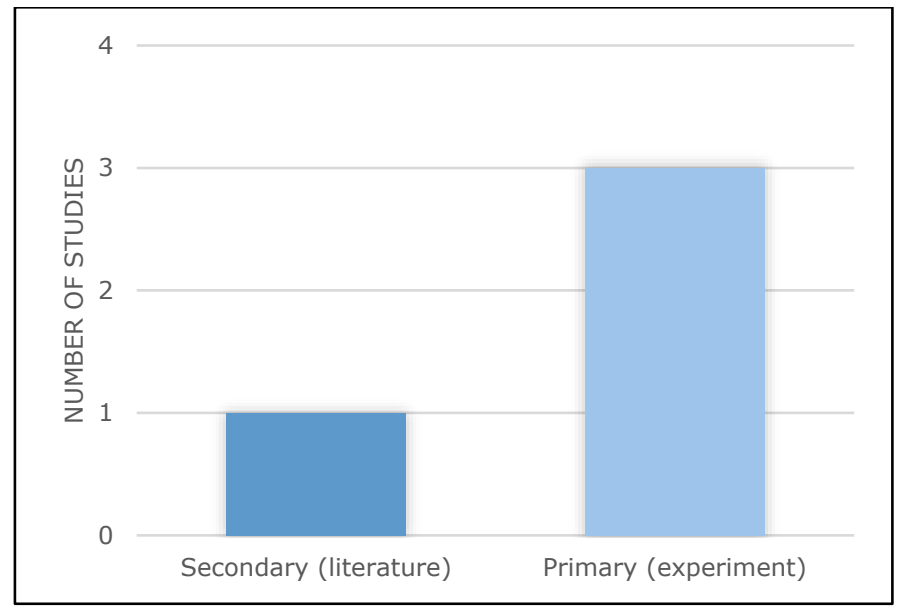

Figure 24 Approaches used in reviewed studies (Cocoa). 
The study by Asora-Finau et al. (2018) reports on weight loss of beans during fermentation, depending on the size of the fermentation box, resulting in a relatively small difference ( $12 \%$ versus $16 \%)$. No distinction was made between losses in bean mass or loss of water content. Nguyen et al. (2019) investigate the difference in weight loss between a process in which the whole beans are first roasted, then broken and winnowed (11.3\% loss), and a process in which the beans are first broken and winnowed, then the nibs are roasted (1.6\% loss). This, however, is a processing loss that is not within the scope of this study. Zulkarnain et al. (2020) show that drying with a swirling fluidized bed (SFB) reduces the drying time of cocoa beans from 11 to 2 days - achieving the same weight loss of approximately 59\%. However, in this evaluation of the drying process, no distinction was made between water loss (the purpose of drying) or dry matter loss ('real' food loss) raising questions as to the usefulness of this information in the scope of this study. Overall, farm characteristics (i.e. whether the studies were undertaken in a smallholder context) were not discussed in these studies.

The published data on post-harvest loss in cocoa is insufficient to draw any firm conclusions on hotspots of loss. In terms of value loss (rather than volume loss), the fermentation and drying stages are recognized as critical by cocoa buyers, as poor practices have a large impact on the quality and price of the product. The studies reviewed show that specific interventions can be implemented in these processes and that tackling pre-harvest threats is particularly relevant. 


\section{Discussion and conclusions}

In the section above, information from previous research about food losses in postharvest on-farm activities in chains of selected (cash) crops was reviewed, and where data allowed, these loss estimates were compiled to obtain a post-harvest loss profile for each crop. Understanding the volumes of losses is considered highly relevant with an eye on food (in)security and environmental impact (amongst which climate change impact) for prioritizing measures and defining strategies for climate change mitigation. Amongst the crops some induce relatively high greenhouse gas emissions (like rice); others induce moderate emissions (like hazelnut (Volpe et al., 2015), sesame (Audsley et al., 2009), quinoa (Vázquez-Rowe et al., 2017)). Thus, choosing appropriate measures that result in the reduction of losses may also fit in climate change mitigation for which integral assessments of indirect effects of loss reduction and additional emissions due to the interventions are needed (Broeze, 2019).

For each crop, the geographical focus of the reviewed studies was compared to the spread of production across the globe. For four of the crops considered (black pepper, chilli pepper, cashews, and sesame), the focal points of research were not the big producer markets, but rather countries with a relatively small share of world production, reflecting the regional bias of researchers or research funders. For other crops, notably cocoa, coffee, hazelnut, quinoa, and to some extent rice, the geographical focus of research matched quite well with the spread of production, but only rice had sufficient studies for reasonable inferences to be drawn about hotspots of loss. It would be unwise to draw generalizations about crop-specific losses from a very small number of studies in a few countries, given different assumptions and methodologies adopted plus the influences of locally specific farm systems and practices are significant. Most studies that specified the farm context indicated a predominant focus on smallholder farms, with a smaller group of other studies (notably for Coffee) looking specifically at large farms and plantations.

In terms of measurements and definitions, the literature reviewed (68 studies in total) was extremely diverse. Loss estimates were included from studies relying on first-hand measurements from farm samples or (controlled) experiments, but also self-reported losses from surveys or interviews, and secondary data from previous research. Whereas methods themselves were generally well described, in case of secondary data, it was often hard to verify where the numbers came from. Overall, the literature was less explicit about definitions of food loss, and often the final destination of lost produce was not specified.

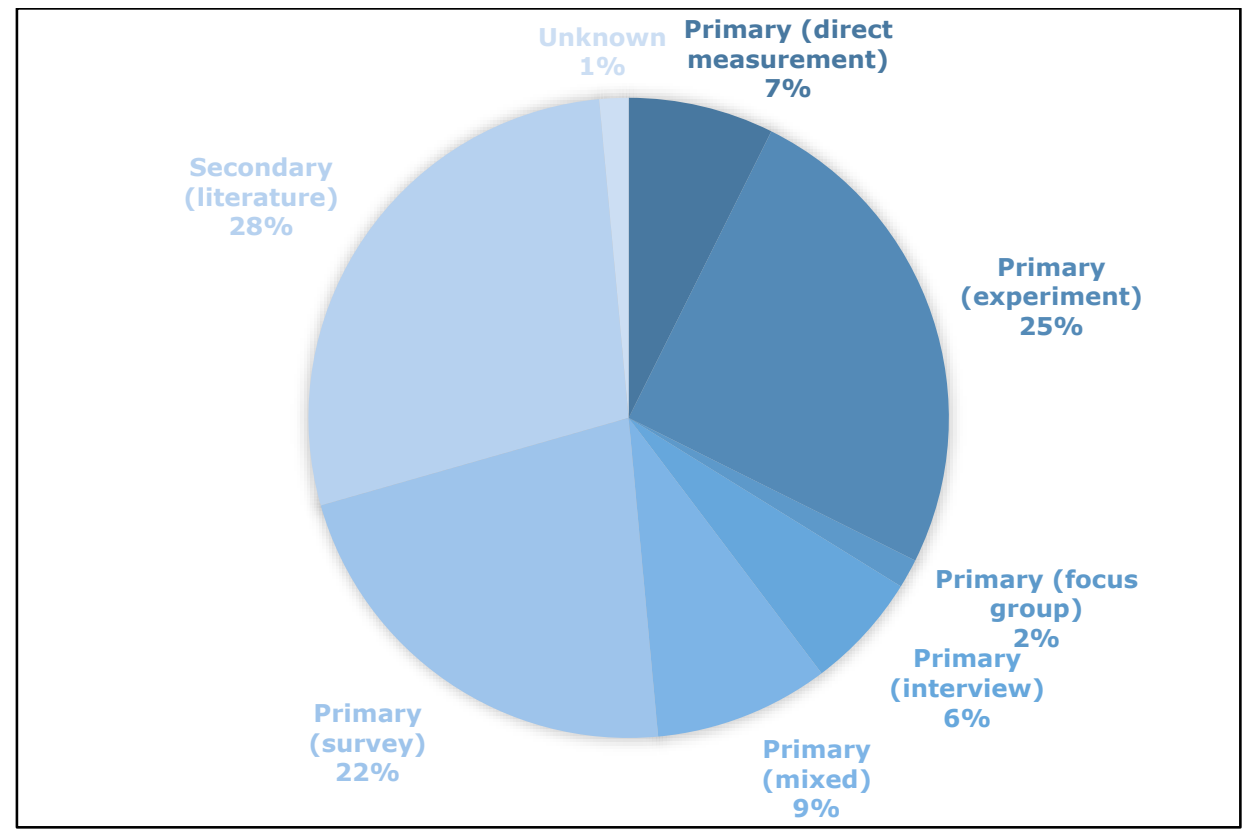

Figure 25 Breakdown of data collection approaches used in reviewed studies. 
A large share of information reported came from sources with questionable reliability, namely from self-reporting by respondents and from secondary sources (with often unclear provenance). Only a relatively small subset of studies report findings from physical measurements. Most of these are experimental, with a more narrow focus on specific activities, and only 5 studies ( $7 \%$ of all studies reviewed) report direct measurements along the chain. The diversity in methods also raised the problem that studies are not readily comparable. With one study that reports losses for all activities, it is easier to point out the probable hot spot, and ideally a loss profile is compiled from these types of studies. However, most loss profiles had to be pieced together from separate studies in different regions using very different methods (direct measurements, experiments, self-reported losses, or secondary data) reporting data on one or only a few activities - with limited comparability.

Overall for all crops, except rice, data availability was very limited. For each activity, often only a few loss estimates were available. Moreover, due to the diversity in methods used and (often not explicitly discussed) production contexts in the studies, results per activity may not be comparable. For activities where relatively more information was available, and for the total on-farm loss range estimates, strongly diverging estimates from the literature resulted in a wide range of possible loss values. As a result, for most crops loss hotspots cannot be identified with any certainty. Table 2 below shows our tentative findings by crop, in terms of data availability, the range of total on-farm loss estimates, and loss hotspots insofar as these could be identified.

Table 3 Summary table of literature review.

\begin{tabular}{|c|c|c|c|c|}
\hline Crop & $\begin{array}{l}\text { Data } \\
\text { availability }\end{array}$ & $\begin{array}{l}\text { Total loss (estimated } \\
\text { upper/lower bound) }\end{array}$ & Hotspot(s) & $\begin{array}{l}\text { Probability of data } \\
\text { reliability }\end{array}$ \\
\hline Rice & Good & $\begin{array}{l}\text { Lower: } 5.76 \text { (best case with } \\
\text { post-harvest interventions) } \\
\text { Upper: } 47.7 \%\end{array}$ & Uncertain, possibly storage & $\begin{array}{l}\text { High - a fairly large number of } \\
\text { relatively comparable studies }\end{array}$ \\
\hline Quinoa & Limited & $\begin{array}{l}\text { Lower: } 9.9 \% \\
\text { Upper: } 38.4 \%\end{array}$ & Possibly processing & $\begin{array}{l}\text { Limited - small number of } \\
\text { studies, with fragmented or } \\
\text { questionable data }\end{array}$ \\
\hline $\begin{array}{l}\text { Chilli } \\
\text { pepper }\end{array}$ & Fair & $\begin{array}{l}\text { Lower: } 7.42 \% \\
\text { Upper: } 44.69 \%\end{array}$ & $\begin{array}{l}\text { Possibly harvest, handling and } \\
\text { transport (strong outlier effect) }\end{array}$ & $\begin{array}{l}\text { Fair - several fairly } \\
\text { comparable studies report } \\
\text { losses }\end{array}$ \\
\hline $\begin{array}{l}\text { Black } \\
\text { pepper }\end{array}$ & Limited & $\begin{array}{l}\text { Lower: } 0.94 \% \\
\text { Upper: } 3.96 \%\end{array}$ & Uncertain (diverging estimates) & $\begin{array}{l}\text { Fair - relatively consistent loss } \\
\text { estimates, but from only two } \\
\text { studies (both in India) }\end{array}$ \\
\hline Cashew & Limited & $\begin{array}{l}\text { Lower: } 1.02 \% \\
\text { Upper: } 3.8 \%\end{array}$ & Possibly harvest, threshing & $\begin{array}{l}\text { Fair - relatively consistent loss } \\
\text { estimates, but from only two } \\
\text { studies (both in India) }\end{array}$ \\
\hline
\end{tabular}

Overall, we conclude that data availability (especially of readily comparable data) for the crops covered in this study is limited, the ranges of possible loss values are wide, and for most crops loss hotspots cannot be identified with certainty.

This conclusion should be considered within the scope of this study, and with the limitations of the study in mind. We only considered the first part of the chain for a number of selected crops, and worked with information available from existing, publicly-accessible research. Therefore, the limitations of this study relate to an important part of the limitations of this body of research. 
The literature reviewed does show unequivocally that interventions upgrading basic traditional practices can result in greater efficiency and/or lower food losses (as was shown in the case of rice, sesame, quinoa, hazelnut, and cocoa), but more precise and actionable information is needed to effectively guide investments and interventions. As of now, there is no established way yet to derive recommendations for interventions from food loss data - most studies focusing on measurement along the chain do not discuss interventions as a next step, and studies that focus on interventions often do not consider these in the context of the entire chain. Future research should focus on cost-efficient approaches to identifying hotspots and quantifying the losses where it matters, in a way that is comparable and can be aggregated across different trials, to improve the availability and quality of information - also in smaller product categories - to support more informed decisions as to where exactly in the chain interventions should be prioritized. 


\section{$5 \quad$ Recommendations}

Food loss reduction is a key path for ensuring food security and climate change mitigation strategies. Post-harvest losses can represent a significant percentage of the total (potential) harvest, and thus negatively impact both the total land and environmental footprint of that crop as well as farmer incomes, food security, and other SDGs related to rural livelihoods.

In the introduction, different food loss data collection methodologies were discussed. General, highlevel food loss data, appropriate for policymakers, can be imputed from FAO's food balance sheets an approach that underpins the great majority of food loss data available worldwide. More relevant for this study is food loss data for specific supply chains, that stakeholders in these chains require to be able to make informed investment decisions on which interventions to implement. This study has shown that there is a considerable deficiency of specific, reliable, and comparable primary data in this domain, specifically in developing countries and upcoming economies. Even for globally traded commodities (such as coffee and cocoa) data on food losses and food loss hotspots is very limited, which prohibits informed investment in food loss reducing interventions. The data deficit not only pertains to the quantity of information available but also to the extent to which loss estimates can be compared. A push for standardization is required in efforts towards a better understanding of postharvest losses, and better alignment of efforts towards identifying and tackling food losses in farm contexts - for example through ISO norms specific for this issue, or a globally agreed code of conduct and standards.

Better methodical alignment is desirable in order to be able to aggregate efforts of numerous parties towards a broader and deeper understanding of food loss. Generally, for research efforts in this domain, better alignment on methodology and reporting is recommended, with the development of shared methods that can be adapted to different crops and contexts yet still ensure consistent reporting. For this, the setting of specific (ISO) standards and code of conducts for food loss data collection is desirable. Measurement and reporting standards should include acknowledgment of (and possibly controlling for) relevant contextual factors, and broader alignment on definitions of food loss, activities, and measurements. Ideally, research efforts on food loss in the farm context should contribute to a coherent and comparable body of information covering a wide range of crops. Besides these issues of streamlining data collection, a stronger focus on impactful interventions is also desirable, with primary data collection serving in the first place to understand the most relevant hotspots in key origin countries where interventions can have the most significant impact, and is conducted with the aim of supporting actionable recommendations for investment decisions.

The study does show that loss-reducing interventions in these chains are very necessary. As selfreported loss estimates seem to underestimate losses, it is likely that from the loss profiles compiled, the true level of losses is likely to be closer to the upper bound of losses - which can reach or even exceed $50 \%$ of production. This underscores the need to identify hot spots for specific crops and select and implement interventions where they can have the most impact. Food loss reducing solutions not only improve profitability along the chain and food security for farmers, but also reduce food loss related greenhouse gas emissions. This multi-faceted impact should be highlighted in funding intervention-oriented research. Evidence-based interventions can be the basis of significant increases in valorized production and more sustainable practices, but to reach the ambitions of the sustainable development goals, time to impact needs to be shortened.

Measuring losses at all activities in specific chains is costly and time-consuming. Clearly, comprehensive measurements are optimal if time and resources are not a critical factor, and are in fact essential when continuous and consistent monitoring of food losses is the main goal. However, in a business environment where improvement of current practices is the main goal, a balance between on the one hand cost and time and on the other hand a trustworthy accuracy level is advised.

For specifically this purpose (i.e. not monitoring or knowledge development, but supporting interventions in specific chains with limited time and budget for measurements), WUR is developing a two-step approach for FLW measurement and intervention selection (Broeze \& Snels, 2020). In the first step experts (actors in the supply chain, government, research, extension services, business 
associations) are asked to identify loss hotspots in a structured process. Although not as precise as direct measurements in quantifying the magnitude of losses, these stakeholders and experts have knowledge of at least where loss hotspots are and thus where measurements are most crucial, facilitating a more targeted approach at lower cost. From this focusing process, the underlying causes are elaborated including intervention options. In case of a low-cost intervention, corresponding action can be taken easily and quickly. Whenever this intervention requires a significant investment, a second step is to conduct targeted on-site measurements of for example a specific chain activity to support business plans, risk and feasibility assessments, and to facilitate access to financing. Also for these measurements, transparency about definitions and methods and quality of implementation and reporting is essential, but the measurements themselves can be more targeted on the relevant hotspots.

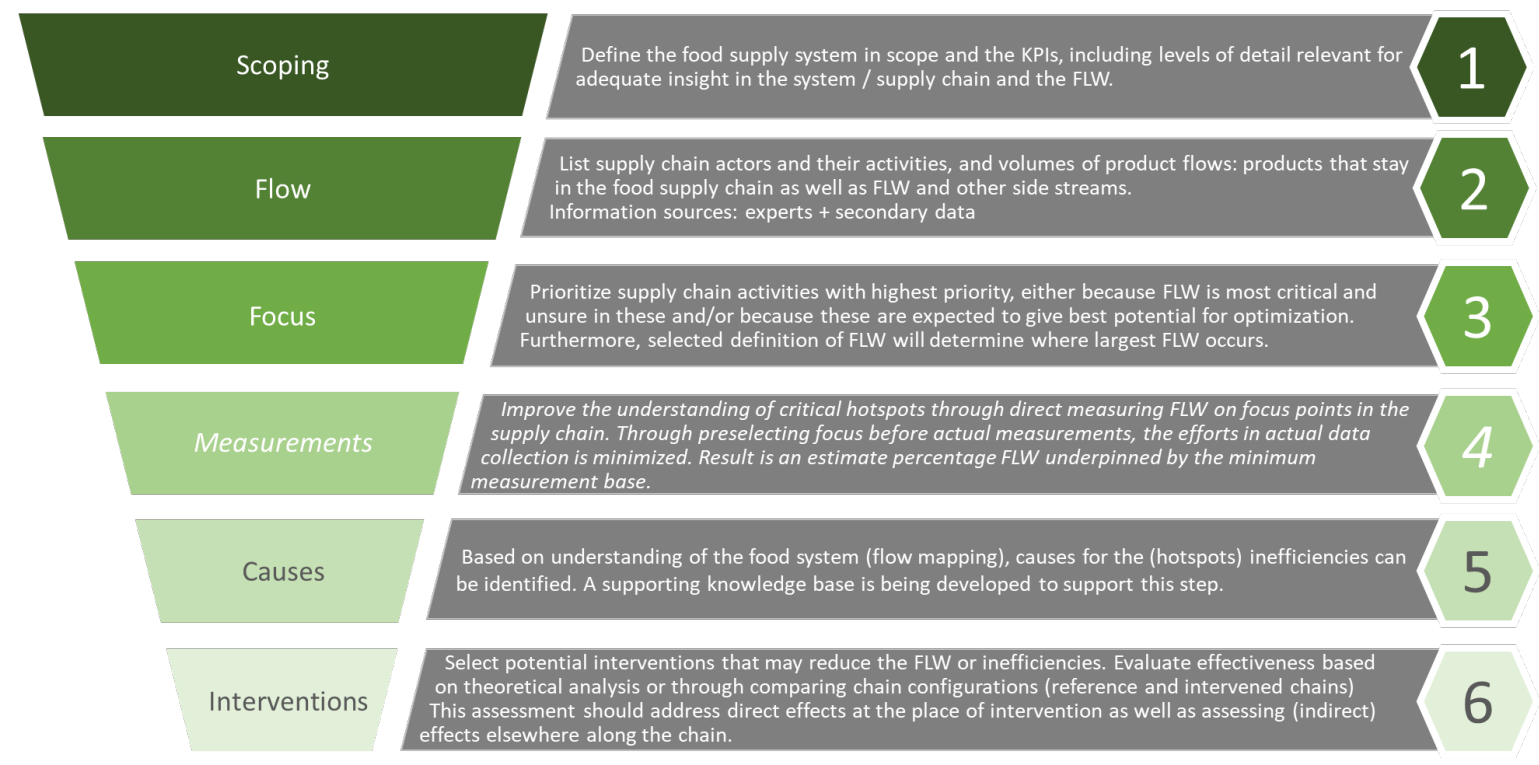

Figure 26 Proposed approach to food loss measurement and interventions (Broeze \& Snels, 2020).

This approach fits a situation where it is necessary or desirable to shorten the time to implementation of interventions with limited time and resources. However, when time and budget are not constraints, more comprehensive measurements are preferred - in the most transparent and standardized way possible.

The ambition to accelerate understanding and mitigation of food losses should extend to the sector itself, where interventions need to be implemented ultimately. Companies and funding organizations should also start to focus on increasing the availability of reliable data on losses in a smallholder farmer context. Companies need to participate actively in identifying hotspots in their chains and work towards interventions. They should align with research institutes on identifying the most effective approach, selecting the best suited and scalable interventions with a minimum of environmental tradeoffs like increase of greenhouse gas emissions, and stimulate and disseminate this work on a global scale. This also requires alignment on methodology, definitions, and reporting. Across the board, we recommend sharing of data and reporting so that verifiable data and actionable information becomes available for each crop and data-driven progress can be shown.

Concluding, with only another 10 years to go, this report calls for more immediate and scalable actions in the above-suggested fields as a requirement for cutting FLW in half to meet SDG 12. Moreover, actions on food loss and waste reduction can help countries meet their commitments to the Paris Agreement on climate change. 


\section{References}

Abay, F., \& Berhe, M. (2014). Report for sesamae post-harvest loss study in Ethiopia.

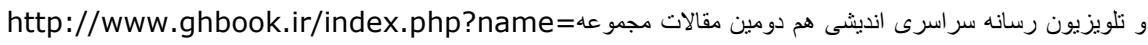
سكو لاريسم\&option=com_dbook\&task=readonline\&book_id=13629\&page=108\&chkhashk=03C706812F\&It emid=218\&lang =fa\&tmpl=component

Abraao, C. V. F., Paulo, S. V., Tafarel, V. C., Wagner, N. R., Marcelo, A. T., Lima, D. M., Sebastiao, V. B. B., Romario, G. F., Aymbire, F. A. da F., Maria, A. G. F., Marcone, C., \& Saul, de A. J. (2018). The permanence in the plantation after harvest damages physical characteristics of Conilon coffee grains. African Journal of Agricultural Research, 13(17), 911-917. https://doi.org/10.5897/ajar2017.12847

Adeigbe, O. O., Olasupo, F. O., Adewale, B. D., \& Muyiwa, A. A. (2015). A review on cashew research and production in Nigeria in the last four decades. Scientific Research and Essays, 10(5), 196-209. https://doi.org/10.5897/sre2014.5953

Alizadeh, M. R., \& Allameh, A. (2013a). Evaluating rice losses in various harvesting practices. International Research Journal of Applied and Basic Sciences, 4(4), 894-901. internalpdf://65.229.97.152/Evaluating-rice-losses-in-various-harvesting-p.pdf

Alizadeh, M. R., \& Allameh, A. (2013b). Evaluating rice losses in various harvesting practices. International Research Journal of Apllied and Basic Sciences, 4(4), 894-901. http://www.irjabs.com/files_site/paperlist/r_767_130422105800.pdf

Appiah, F., Guisse, R., \& Dartey, P. K. A. (2011). Post harvest losses of rice from harvesting to milling in Ghana. Journal of Stored Products and Postharvest Research, 2(4), 64-71. internalpdf://159.194.55.164/Post-harvest-losses-of-rice-from-harvesting-to.pdf

Asora-Finau, K., Pele, S., Okesene, A., Brunt, D., \& Tuu'u, K. (2018). On-farm trials for proven cocoa fermentation and drying method (Issue May).

Audsley, E., Brander, M., Chatterton, J., Murphy-bokern, D., Webster, C., \& Williams, A. (2009). How Low Can We Go? An assessment of greenhouse gas emissions from the UK food system and the scope to reduce them by 2050. WWF-UK and Food Climate Research Network, January, 1-83. http://scholar.google.com/scholar?hl=en\&btnG=Search\&q=intitle:HOW+LOW+CAN+WE+GO?\#0\%255 Cnhttp://assets.wwf.org.uk/downloads/how_low_report_1.pdf

Avelino, J., Allinne, C., Cerda, R., Willocquet, L., \& Savary, S. (2018). Multiple-disease system in coffee: From crop loss assessment to sustainable management. Annual Review of Phytopathology, 56, 611635. https://doi.org/10.1146/annurev-phyto-080417-050117

Bala, B. K., Haque, M. A., Hossain, M. A., \& Majumdar, S. (2010). Post harvest loss and technical efficiency of rice, wheat and maize production system: Assessment and measures for strengthening food security. internal-pdf://0661492495/3.pdf

Berhe, M., Abraha, B., Terefe, G., \& Walle, M. (2011). Sesame harvest loss caused by sesame seed bug, Elasmolomus sordidus F. at Kafta-Humera sesame fields. SINET: Ethiopian Journal of Science, 31(2), 147-150. https://doi.org/10.4314/sinet.v31i2.66645

Beyhan, M. A., Tekgüler, A., Yildiz, T., \& Sauk, H. (2009). Investigation of the performance of a hazelnut husker design used in Turkey. Biosystems Engineering, 103(2), 159-166. https://doi.org/10.1016/j.biosystemseng.2008.10.006

Broeze, J. (2019). Agro-Chain Greenhouse Gas Emissions (ACGE) calculator.

Broeze, J., \& Snels, J. (2020). Consortium Webinar: Post Harvest Food Loss \& Waste Monitoring Protocol. https://www.youtube.com/watch?v=3GsSx9LCIZ4

Brook, A. J., Murphy, S. T., Kenny, M. K., Shaw, W., Kukhang, T., Aranka, J., Simbiken, N., Walton, T., \& Curnow, J. (2015). Coffee green scales in Papua New Guinea: highland arabica coffee and yield loss. September.

Caldeira, C., Corrado, S., \& Sala, S. (2017). Food waste accounting. Methodologies, challenges and opportunities. In JRC Technical Reports. Publications Office of the European Union. https://doi.org/10.2760/957031

Cerkauskas, R. F., Brown, J., Ferguson, G., \& Khosla, S. (1999). First report of powdery mildew of greenhouse pepper caused by Leveillula taurica in Canada. Plant Disease, 781.

Commission for Environmental Cooperation. (2019). Why and How to Measure Food Loss and Waste: A Practical Guide. Commission for Environmental Cooperation.

Corrado, S., Caldeira, C., Eriksson, M., Hanssen, O. J., Hauser, H. E., van Holsteijn, F., Liu, G., Östergren, K., Parry, A., Secondi, L., Stenmarck, A., \& Sala, S. (2019). Food waste accounting methodologies: Challenges, opportunities, and further advancements. Global Food Security, 20, 93-100. https://doi.org/10.1016/j.gfs.2019.01.002

Danielsen, S., \& Munk, L. (2004). Evaluation of disease assessment methods in quinoa for their ability to 
predict yield loss caused by downy mildew. Crop Protection, 23(3), 219-228.

https://doi.org/10.1016/j.cropro.2003.08.010

De Lucia, M., \& Assennato, D. (1993). La ingenieria en el desarrollo - Manejo y tratamiento de granos poscosecha.

De Wit, L. (2014). The influence of absenteeism on the Turkish hazelnut sector. http://edepot.wur.nl/299847

Desale, G., Jema, H., \& Bosena, T. (2019). Sesame post-harvest loss from small-scale producers in Kafta Humera District, Ethiopia. Journal of Development and Agricultural Economics, 11(2), 33-42. https://doi.org/10.5897/jdae2017.0917

Drambi, U. D., Saeed, H. A., Abubakar, L. G., Mohammed, A. A., \& Bashir, U. (2017). Development and performance evaluation of a pedal operated paddy rice winnower for small scale rural farmers in Nigeria. Int. J. Sci. Qual. Anal, 3, 37-41.

Fabi, C. (2019). EU Meeting on Food Loss Measurement. Experiences and recommendations for quantifying food loss and waste from primary production.

FAO. (2011). Global food losses and food waste. Extent, causes and prevention. https://doi.org/10.4337/9781788975391

FAO. (2020). FAOstat. http://www.fao.org/faostat/en/

Gauraha, A., \& Thakur, B. (2008). Comparative economic analysis of post-harvest losses in vegetables and foodgrains crops in Chhattisgarh. Indian Journal of Agricultural Economics, 63(3), 376.

Gharde, Y., Singh, P. K., Dubey, R. P., \& Gupta, P. K. (2018). Assessment of yield and economic losses in agriculture due to weeds in India. Crop Protection, 107(August 2017), 12-18. https://doi.org/10.1016/j.cropro.2018.01.007

Grosse-Ruschkamp, A., \& Seelige, K. (2010). Analysis of the cashew value chain in Mozambique.

Gummert, M. (2012). Improved postharvest technologies and management for reducing postharvest losses in rice. II Asia Pacific Symposium on Postharvest Research Education and Extension: APS2012 1011, 63-70. internal-pdf://146.163.194.199/4.pdf

Guo, X., Broeze, J., Groot, J., Axmann, H., \& Vollebregt, M. (2020). A worldwide hotspot analysis on food loss and waste, associated greenhouse gas emissions, and protein losses. Sustainability, 12, 7488.

Hayes, R. A. (2017). Human Centered Design of an Open-Drum, Treadle Thresher for Quinoa Farmers in the Andes of Northern Peru. Michigan Technological University, 1-43. http://digitalcommons.mtu.edu/etdr/435/

Hodges, R. (2013). How to assess postharvest cereal losses and their impact on grain supply. Rapid weight loss estimation and the calculation of cumulative cereal losses with the support of APHLIS.

Ishpekov, S., Naydenov, N., Zaykov, R., Stamatov, S., \& Ruschev, D. (2017). Releasing of seeds by a lateral mechanical impact for feeding sesame stems into harvester. Agricultural Engineering International: CIGR Journal, 19(4), 54-60.

Ishpekov, S., \& Stamatov, S. (2013). Sesame harvesting with grain harvester in conditions of Bulgaria.

Ishpekov, S., \& Stamatov, S. (2019). Overview of sesame research in bulgaria. International Scientific Journal "Mechanization in Agriculture," 24(1), 17-24.

Islam, A. H. M. S., Schreinemachers, P., \& Kumar, S. (2020). Farmers' knowledge, perceptions and management of chili pepper anthracnose disease in Bangladesh. Crop Protection, 133(March), 105139. https://doi.org/10.1016/j.cropro.2020.105139

Jahagirdar, S., \& Siddaramaiah, A. L. (2000). Estimation of avoidable loss due to foot rot of black pepper. Karnataka Journal of Agricultural Sciences, 13(4), 1019-1021. http://14.139.155.167/test5/index.php/kjas/article/view/4028

Jang, C., Kahn, N., Langlois, L., Liu, R., \& Montanaro, G. (2014). Design of a Winnowing Machine for West African Rice Farmers. Department of Bioresource Engineering, McGill University.

Jang, C., \& Montanaro, G. (2014). Design of a Winnowing Machine for West African Rice Farmers. 1-23.

Jha, S. N., Vishwakarma, R. K., Ahmad, T., Rai, A., \& Dixit, A. K. (2015). Report on Assessment of Quantitative Harvest and Post-Harvest Losses of Major Crops / Commodities in India. https://doi.org/10.13140/RG.2.1.3024.3924

Kasso, M., \& Bekele, A. (2018). Post-harvest loss and quality deterioration of horticultural crops in Dire Dawa Region, Ethiopia. Journal of the Saudi Society of Agricultural Sciences, 17(1), 88-96. https://doi.org/10.1016/j.jssas.2016.01.005

Kelali, K., Misikir, M., \& Kormelinck, A. . (2014). Sesame yields and post-harvest losses in Ethiopia: Evidence from the field. http://dx.doi.org/10.1016/j.foodchem.2010.03.044\%0ABMC Genetics\%0Ahttp://genomebiology.com/2014/15/2/R39\%5Cnpapers3://publication/doi/10.1186/gb2014-15-2r39\%0Ahttp://dx.doi.org/10.1016/j.jchromb.2014.06.033\%0Ahttp://dx.doi.org/10.1038/ncomms9609 $\% 0 A h t t p:$

Kok, M. G., \& Snel, H. (2019). Food loss measurements in the rice supply chain of Olam Nigeria.

Kumar, D., \& Kalita, P. (2017). Reducing postharvest losses during storage of grain crops to strengthen food security in developing countries. Foods, 6(1), 8. internal-pdf://0259434457/15.pdf 
Lalhmangaihchhungi, H. (2018). Post-Harvest Loss and Management Practices of Agriculture Produces under Shifting Cultivation in Mizoram.

Lopes, D. de C., \& Steidle Neto, A. J. (2020). Modelling the dry matter loss of coffee beans under different storage conditions. Journal of Stored Products Research, 88. https://doi.org/10.1016/j.jspr.2020.101669

Markuszewski, B., \& Kopytowski, J. (2015). Effects of Storage Conditions on the Quality of Unripe Hazelnuts in the Husk. Journal of Horticultural Research, 23(2), 59-67. https://doi.org/10.2478/johr-2015-0016

Moreno Cárdenas, E. L., Oliveros Tascón, C. E., \& Álvarez Mejía, F. (2015). A Portable Device to Assist in the Harvest of Coffee in Colombia. Revista Facultad Nacional de Agronomía Medellín, 68(1), 7471-7479. https://doi.org/10.15446/rfnam.v68n1.47833

Mukantwali, C., Kabayiza, E., Chahine-Tsouvalakis, H., Vasanthakaalam, H., Kitinoja, L., \& Wheeler, L. (2018). Postharvest loss assessment of green chilies in Rwanda. https://horticulture.ucdavis.edu/sites/g/files/dgvnsk1816/files/extension_material_files/Postharvest Loss Assessment of Green Bananas in Rwanda.pdf

Myint, D., Gilani, S. A., Kawase, M., \& Watanabe, K. N. (2020). Sustainable sesame (Sesamum indicum L.) production through improved technology: An overview of production, challenges, and opportunities in Myanmar. Sustainability (Switzerland), 12(9), 1-21. https://doi.org/10.3390/SU12093515

Narayana, C. K., Pandey, B. K., Malhotra, S. K., \& Pandey, V. (2014). Post harvest losses in selected fruits and vegetables in India (A Compilation).

Nath, B. C., Hossen, M. A., Islam, A., Huda, M. D., Paul, S., \& Rahman, M. A. (2016). Postharvest loss assessment of rice at selected areas of Gazipur district. Bangladesh Rice Journal, 20(1), 23-32. internal-pdf://243.130.253.243/12.pdf

Nguyen, H. B., Pham, D. L., \& Nguyen, V. L. (2019). A study on the breaking and winnowing machine for cocoa beans at small industrial scale in vietnam. International Journal on Advanced Science, Engineering and Information Technology, 9(1), 329-335. https://doi.org/10.18517/ijaseit.9.1.7765

Oduor, G. I., \& Simons, S. A. (2003). Biological control in IPM for coffee. In P. Neuenschwander, C. Borgemeister, \& J. Langewald (Eds.), Biological control in IPM systems in Africa (pp. 347-362). https://doi.org/10.1079/9780851996394.0347

Osei-Kwarteng, M., Mahunu, G. K., Abu, M., \& Darko, G. (2012). 1004 Assessment of Postharvest Losses in Chilli Pepper ( Capsicum annuum cv . Legon 18 ) in the Kwahu North District, Ghana. 1st All Africa Postharvest Congress, 17-19.

Otieno, H. M. O., Alwenge, B. A., \& Okumu, O. O. (2019). Coffee Production Challenges and Opportunities in Tanzania: The Case Study of Coffee Farmers in Iwindi, Msia and Lwati Villages in Mbeya Region. Asian Journal of Agricultural and Horticultural Research, June, 1-14. https://doi.org/10.9734/ajahr/2019/v3i229993

Priyashantha, A. K. H., Krishanthiny, K., \& Mahendranathan, C. (2020). Pre and Post - Harvest Losses of Cashew (Anacardium occidentale L .) in Batticaloa District, Sri Lanka ; Preliminary Investigation of the Causes. International Journal of Research Publications, 43(1). http://ijrp.org/paper-detail/875

Quiroga, C., Escalera, R., Aroni, G., Bonifacio, A., González, J. A., Villca, M., Saravia, R., \& Ruiz, A. (2017). Section 3 Nutritional and Technical Aspects. January 2015. http://www.fao.org/3/ai4042e/i4042e14.pdf

Ramana, K. V., Mohandas, C., \& Eapen, S. J. (1994). Plant Parasitic Nematodes and Slow Decline Disease of Black Pepper.

Ravindra, H., Sehgal, M., Manu, T. G., Murali, R., Latha, M., \& Narasimhamurthy, H. B. (2014). Incidence of root-knot nematode (Meloidogyne incognita) in black pepper in Karnataka. Journal of Entomology and Nematology, 6(4), 51-55. https://doi.org/10.5897/jen2013.0089

Rojas, W., Soto, J. L., \& Carrasco, E. (2004). Study on the Social , Environmental and Economic Impacts of Quinoa Promotion in Bolivia.

Schreinemachers, P., Balasubramaniam, S., Boopathi, N. M., Ha, C. V., Kenyon, L., Praneetvatakul, S., Sirijinda, A., Le, N. T., Srinivasan, R., \& Wu, M. H. (2015). Farmers' perceptions and management of plant viruses in vegetables and legumes in tropical and subtropical Asia. Crop Protection, 75(June), 115-123. https://doi.org/10.1016/j.cropro.2015.05.012

Selvi, R. V, Kalpana, R., \& Rajendran, P. (2002). Pre and post harvest technologies to reduce yield losses in rice-A review. Agricultural Reviews, 23(4), 252-261. internal-pdf://5.206.72.121/6.pdf

Sharma, G., \& Singh, S. P. (2011). Economic Analysis of Post-harvest Losses in Marketing of. Agricultural Economics Research Review, 24(December), 309-315.

Shavgulidze, R., \& Zvyagintsev, D. (2017). Technical efficiency in the Georgian hazelnut supply chain and policy recommendations. SV EAAE Congress - Towards Sustainable Agri-Food Systems: Balancing between Markets and Society, 51(1), 51.

Shil, S., Mandal, J., \& Das, S. P. (2018). Evaluation of postharvest quality of four local chilli (Capsicum frutescens) genotypes of Tripura under zero energy cool chamber. 7(3), 3698-3702.

Stathers, T., Holcroft, D., Kitinoja, L., Mvumi, B. M., English, A., Omotilewa, O., Kocher, M., Ault, J., \& 
Torero, M. (2020). A scoping review of interventions for crop postharvest loss reduction in subSaharan Africa and South Asia. Nature Sustainability, 3(10), 821-835.

https://doi.org/10.1038/s41893-020-00622-1

Sudheendra, A. A. (2005). Studies on Loss Assessment, Epidemiology and Management of Powdert Mildew of Chilli Caused By Leveillula Taurica ( Lev .) Arn ). Dharwad University of Agricultural Sciences.

The Food Waste Atlas. (2020). Food Waste Records. https://thefoodwasteatlas.org/

USAID. (n.d.). Integrated pest management for hazelnut crops. A practical handbook.

Vázquez-Rowe, I., Larrea-Gallegos, G., Villanueva-Rey, P., \& Gilardino, A. (2017). Climate change mitigation opportunities based on carbon footprint estimates of dietary patterns in Peru. PLOS ONE, 12(11), 1-25. https://doi.org/10.1371/journal.pone.0188182

Veronica, D., Renata, A. A. dos S., Arthur, S. B. L., Marcelo, B. da S., Adriano, A. F., \& Antelmo, R. F. (2016). Evaluation of in vitro inhibition of mycelial growth of Fusarium solani f. sp. piperis by different products in Brazil. African Journal of Microbiology Research, 10(47), 1992-1998. https://doi.org/10.5897/ajmr2016.8292

Volpe, R., Messineo, S., Volpe, M., \& Messineo, A. (2015). Carbon footprint of tree nuts based consumer products. Sustainability (Switzerland), 7(11), 14917-14934. https://doi.org/10.3390/su71114917

Wessel, M., \& Quist-Wessel, P. M. F. (2015). Cocoa production in West Africa, a review and analysis of recent developments. NJAS - Wageningen Journal of Life Sciences, 74-75, 1-7. https://doi.org/10.1016/j.njas.2015.09.001

Xue, L., Liu, G., Parfitt, J., Liu, X., Van Herpen, E., Stenmarck, Å., O'Connor, C., Östergren, K., \& Cheng, S. (2017). Missing Food, Missing Data? A Critical Review of Global Food Losses and Food Waste Data. Environmental Science and Technology, 51(12), 6618-6633. https://doi.org/10.1021/acs.est.7b00401

Yusuf, B. L., \& He, Y. (2011). Design, development and techniques for controlling grains post-harvest losses with metal silo for small and medium scale farmers. African Journal of Biotechnology, 10(65), 1455214561. https://doi.org/10.5897/ajb11.1845

Zulkarnain, M. A., Shahriman, M. K., \& Yudin, A. S. M. (2020). Experimental study of drying characteristics of cocoa bean in a swirling fluidized bed dryer. IOP Conference Series: Materials Science and Engineering, 863(1). https://doi.org/10.1088/1757-899X/863/1/012048 



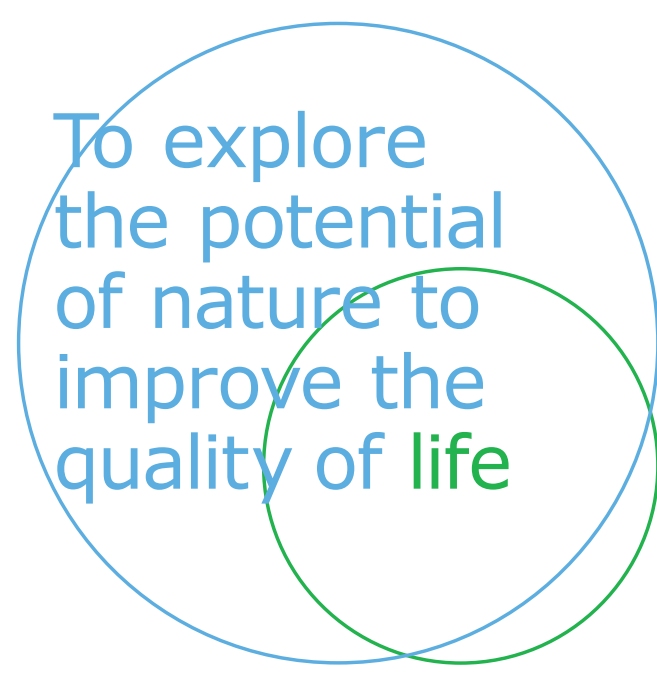

Wageningen Food \& Biobased Research Bornse Weilanden 9

6708 WG Wageningen

The Netherlands

www.wur.eu/wfbr

Einfo.wfbr@wur.nl

Report 2104

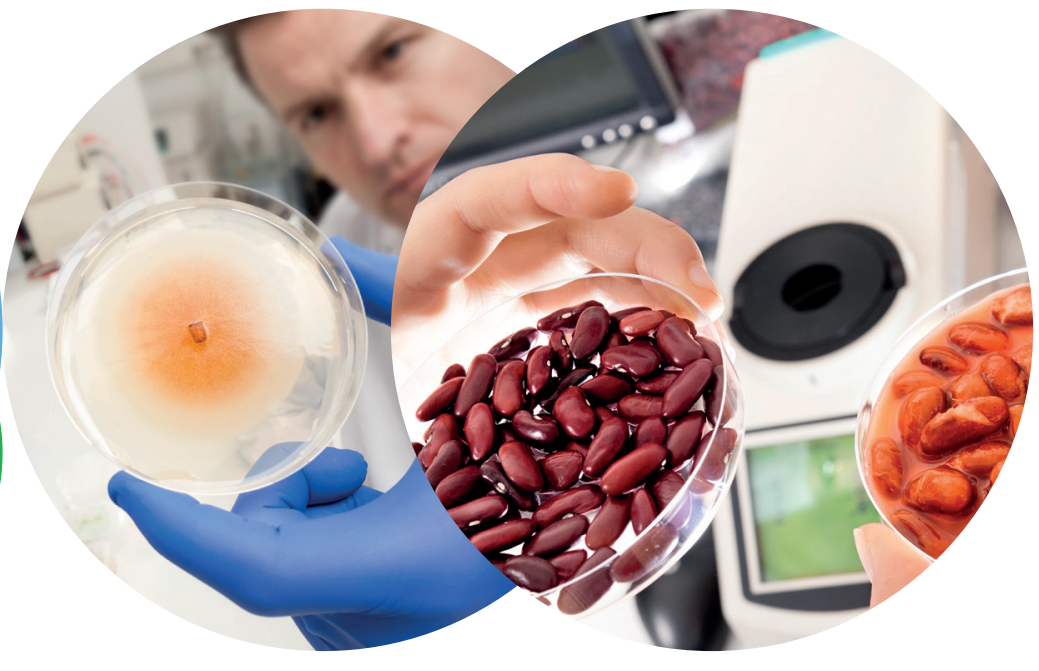

The mission of Wageningen University and Research is "To explore the potential of nature to improve the quality of life". Under the banner Wageningen University \& Research, Wageningen University and the specialised research institutes of the Wageningen Research Foundation have joined forces in contributing to finding solutions to important questions in the domain of healthy food and living environment. With its roughly 30 branches, 6,500 employees (5,500 fte) and 12,500 students, Wageningen University \& Research is one of the leading organisations in its domain. The unique Wageningen approach lies in its integrated approach to issues and the collaboration between different disciplines. 